\section{SANDIA REPORT}

SAND98-1076 • UC-722

Unlimited Release

Printed May 1998
RECEIVED

JUN 033998

OSTI

\title{
A Review of Modeling Issues and Analysis Methods for the Thermal Response of Cargoes Transported in the Safe Secure Trailer Subjected to Fire Environments
}

DISTRIBUTION OF THS DOCUMENT IS UNUMTED P

John R. Howell, Marvin E. Larsen

Prepared by

Sandia National Laboratories

Albuquerque, New Mexico 87185 and Livermore, California 94550

Sandia is a multiprogram laboratory operated by Sandia Corporation, a Lockheed Martin Company, for the United States Department of

Energy under Contract DE-AC04-94AL85000.

Approved for public release; further dissemination unlimited.

\section{Sandia National Laboratories}


Issued by Sandia National Laboratories, operated for the United States Department of Energy by Sandia Corporation.

NOTICE: This report was prepared as an account of work sponsored by an agency of the United States Government. Neither the United States Government nor any agency thereof, nor any of their employees, nor any of their contractors, subcontractors, or their employees, makes any warranty, express or implied, or assumes any legal liability or responsibility for the accuracy, completeness. or usefulness of any information. apparatus, product, or process disclosed, or represents that its use would not infringe privately owned rights. Reference herein to any specific commercial product, process, or service by trade name, trademark manufacturer or otherwise, does not necessarily constitute or imply its endorsement, recommendation, or favoring by the United States Government, any agency thereof, or any of their contractors or subcontractors. The views and opinions expressed herein do not necessarily state or reflect those of the United States Government, any agency thereof, or any of their contractors.

Printed in the United States of America. This report has been reproduced directly from the best available copy.

Available to DOE and DOE contractors from

Office of Scientific and Technical Information

P.O. Box 62

Oak Ridge, TN 37831

Prices available from (615) 576-8401, FTS 626-8401

Available to the public from

National Technical Information Service

U.S. Department of Commerce

5285 Port Royal Rd

Springfield, VA 22161

NTIS price codes

Printed copy: A03

Microfiche copy: A01

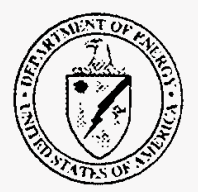




\title{
A Review of Modeling Issues and Analysis Methods for the Thermal Response of Cargoes Transported in the Safe Secure Trailer Subjected to Fire Environments
}

\author{
John R. Howell \\ Department of Mechanical Engineering \\ The University of Texas at Austin \\ Austin, Texas 78712-1063 \\ (Under SNL Contract AO-4796) \\ and \\ Marvin E. Larsen \\ High Consequence Assessment and Technology Department 6314 \\ Sandia National Laboratories \\ P.O. Box 5800 \\ Albuquerque, New Mexico 87185
}

\begin{abstract}
This paper discusses thermal analysis in support of probabilistic risk assessment (PRA) to predict the heating of cargoes shipped in vehicles like the Safe Secure Trailer. Fire environments contribute very significantly to the risk associated with ground transport of special nuclear materials. The tradeoff between thermal model complexity and the affordable number of scenarios used to represent the "hazard space" is discussed as it impacts PRA. The relevant heat transfer mechanisms are discussed along with the applicability of methods from the literature for analysis of these mechanisms. Many of the subject's real problems remain too complex for affordable and rigorous analysis. Available models are generally restricted to idealizations that are quickly obviated by real effects. Approximate treatment methods, striving to produce conservative, realistic estimates are also discussed.
\end{abstract}




\section{Table of Contents}

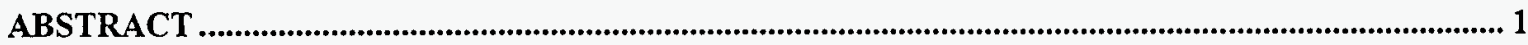

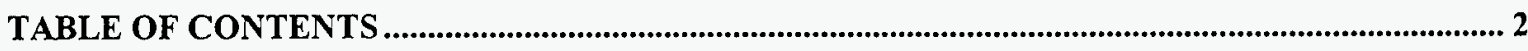

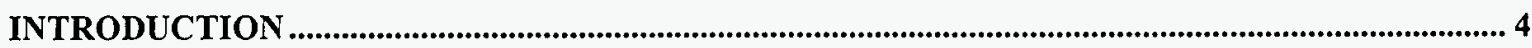

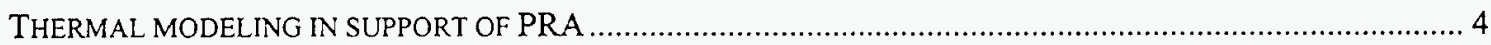

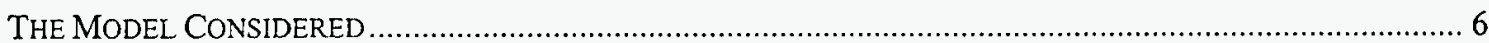

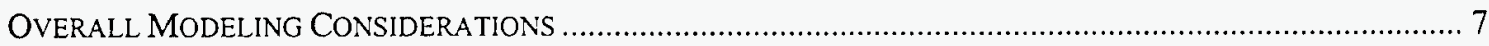

MODELING OF INDIVIDUAL HEAT TRANSFER MODES .............................................................. 8

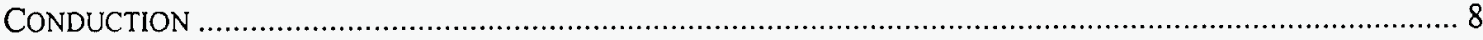

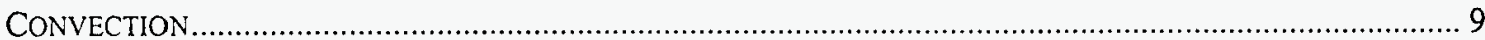

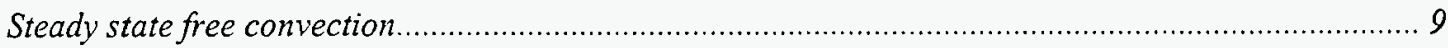

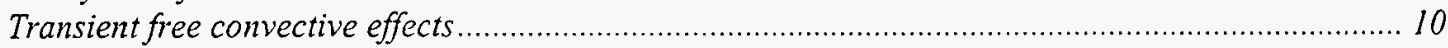

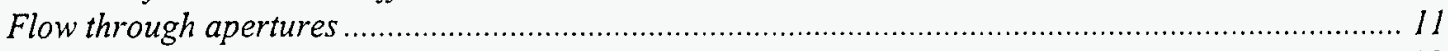

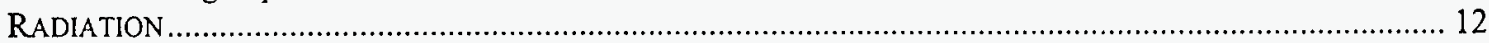

Modeling of radiation from a pool fire to the trailer................................................................... 12

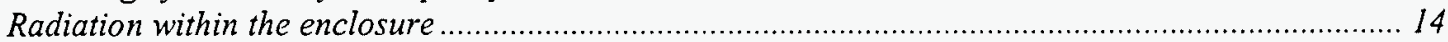

MODELING APPLIED TO THE TRANSPORT SYSTEM ....................................................................... 14

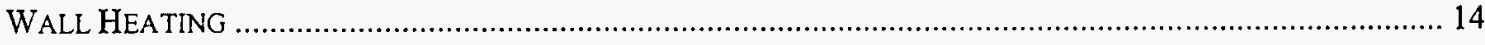

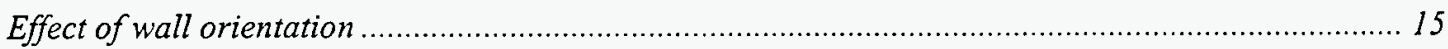

EFFECT OF RADIATION/CONVECTION COUPLING TO TRANSIENT CONDITIONS ON INTERNAL TRAILER

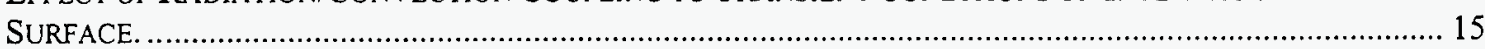

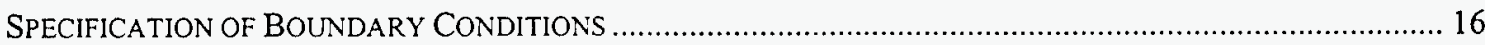

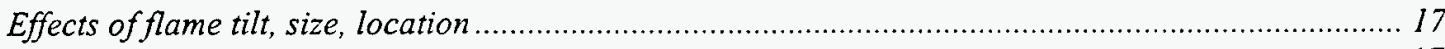

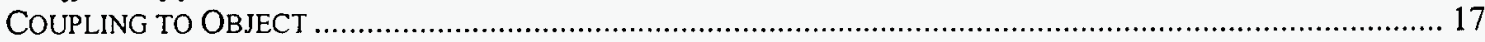

Effect of payload characteristics (shape, composition, properties, configuration of layers) ................ 18

Magnitude of retardation of heat transfer due to radiativelfree convective coupling ............................ 18

Retardation due to geometry/location of object (flow restriction) .................................................... 18

Effects on radiative transfer of coupling to free convection ......................................................... 19

EFFECTS ON RADIATIVE TRANSFER OF COUPLING TO THE PAYLOAD ...................................................... 20

VALIDATION AND VERIFICATION ............................................................................................................ 21

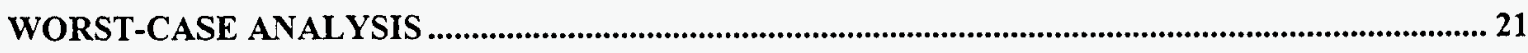

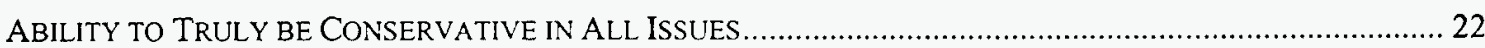

Minimum dimensions (1-D, 2-D, 3-D) necessary for accurate modeling and for WCA modeling .......... 22

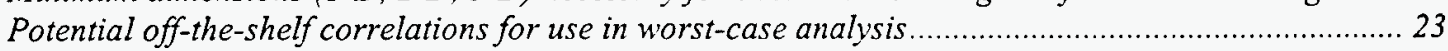

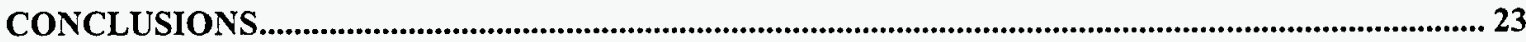

APPENDIX : REVIEW OF RECENT RESEARCH ON FREE CONVECTION IN ENCLOSURES... 25

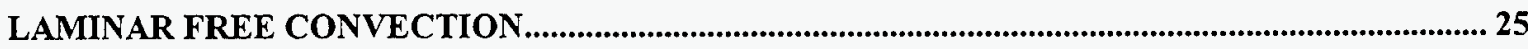

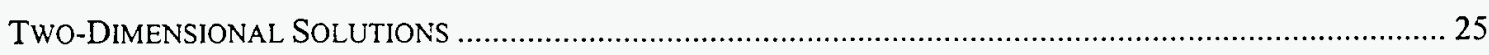

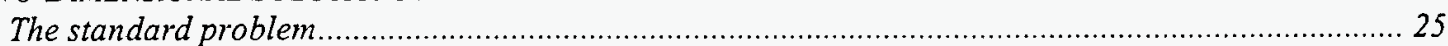

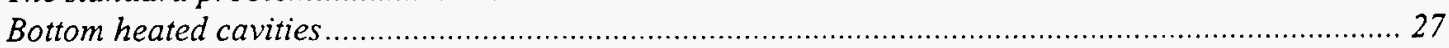

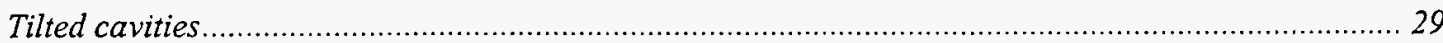

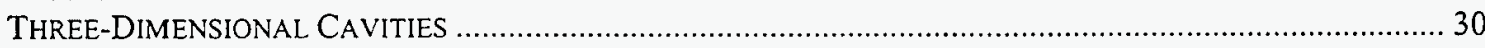




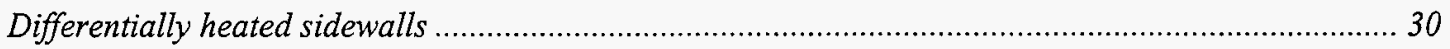

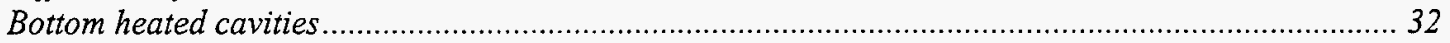

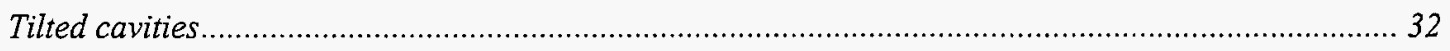

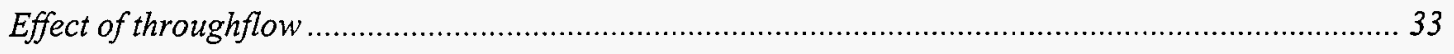

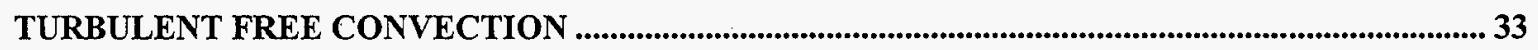

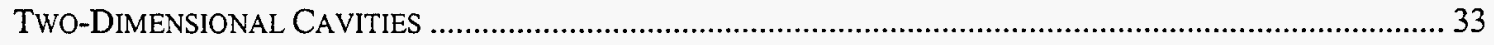

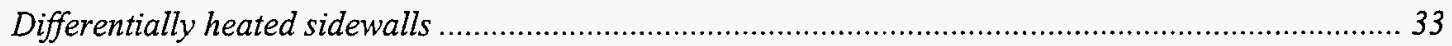

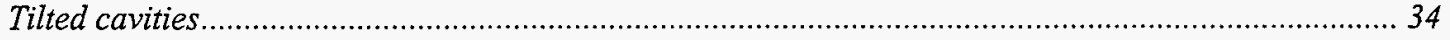

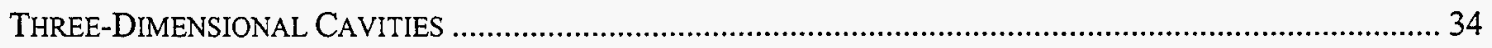

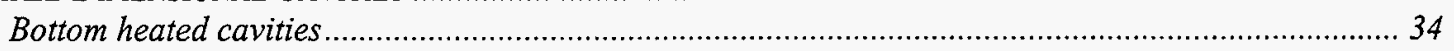

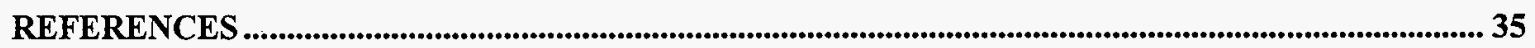

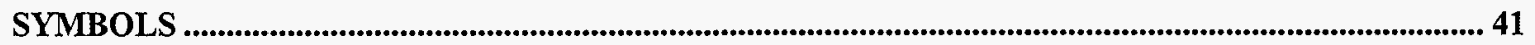

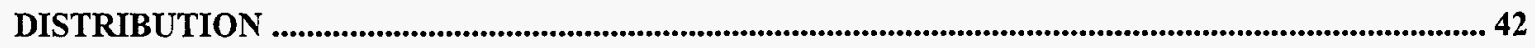




\section{Introduction}

\section{Thermal modeling in support of PRA}

A primary source of risk associated with the present ground shipment methods is due to thermal failure of cargoes held in an SST subjected to a fire environment. Two principal processes are involved in a meaningful risk assessment of the system:

- Deduce the most important parameters that characterize perceived threats and ascribe probabilities to their occurrence consistent with the shipment campaign of interest.

- Estimate system response to specific scenarios posed in terms of the identified important parameters.

In practice, these processes become coupled. The most important parameters might be only discovered by observing their effect on the system response as predicted by the thermal model. Since thermal modeling of real systems is limited, a thermal model is sought that is discerning for the most probable scenarios near the failure surface.

The model's accuracy is of lesser concern for extremely improbable events, very severe environments, or very benign environments as these events either don't figure prominently in the overall result or the outcome may be guessed satisfactorily. The surface shown in Figure 1 represents, in qualitative terms, the relationship between the quality of the final assessment and the thermal model and scenario representation resolution. Neither great thermal modeling or fine resolution of the scenario space can deliver in the absence of the other. Each becomes more expensive when supporting more of the other.

In the DPTRA study (Clauss et al., 1994) a substantial effort was expended to characterize the probability of threatening accident parameters (Clauss et al., 1994). The model MELTER (Larsen, 1994) was developed to affordably provide thermal response estimates over the whole parameter space.

Resolving the representation of the scenario space consists of: 1) characterizing the environment in which the system operates and 2) identifying important modes of system response to be modeled. The former is largely a degree of data collection and rendering into a suitable statistical description. The systems under study are specialized and carefully operated so that a historical database of failure instances does not exist. The system response to environments is deduced from prior testing in other environments and analysis.

Thermal modeling that is relatively detailed in comparison to MELTER is readily achievable for a small number of scenarios. Careful application of boundary conditions and model discretization are still laborious enough to preclude consideration of a large number of scenarios (which need to be duplicated for a number of cargoes). Fewer, more carefully modeled scenarios, may yield important insights. However, to support probabilistic risk assessment the chosen scenarios must reasonably span all plausible scenarios near the failure surface and their relative likelihood must be estimated. 


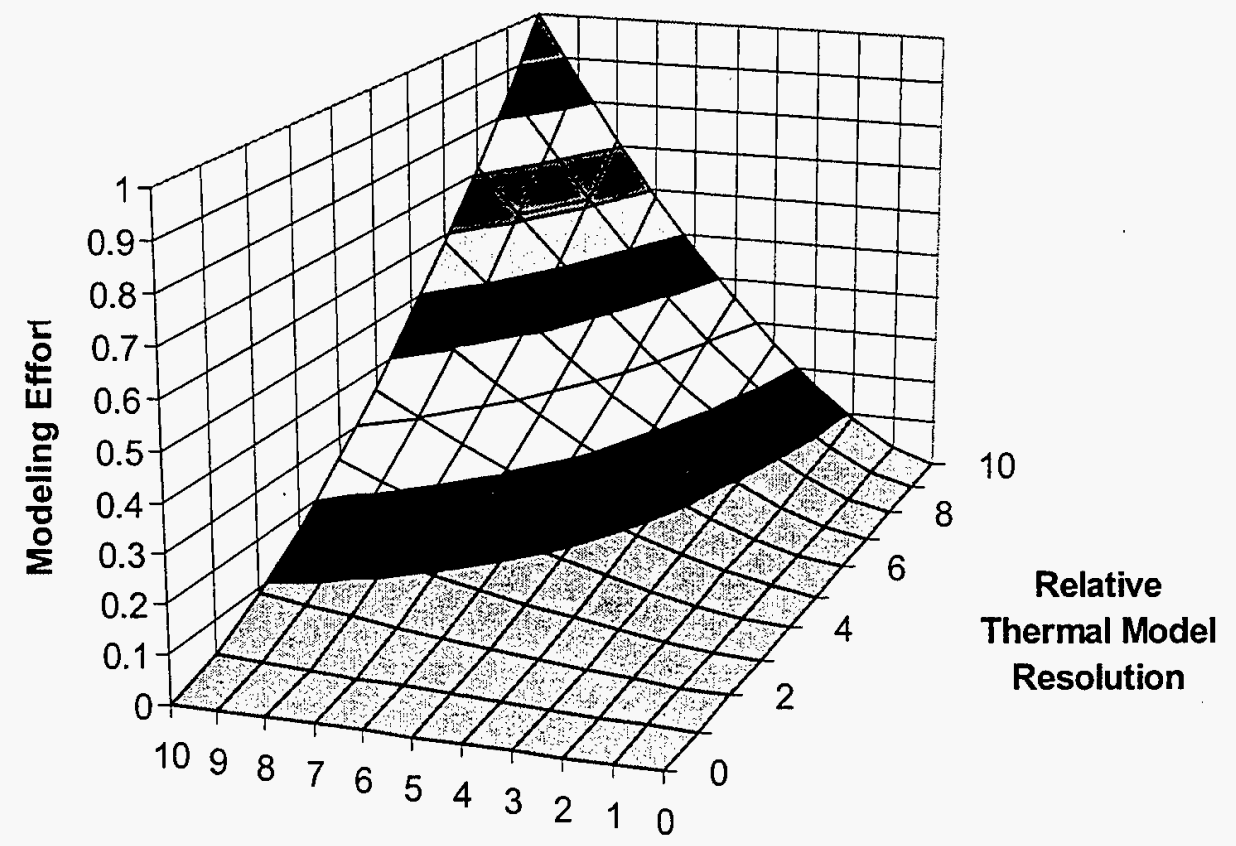

Relative Scenario Resolution

Figure 1: Effect of Model and Scenario Resolution on Modeling Effort

The dilemma is clear, the solution is not. The greatest affordable thermal modeling is desired without limiting the cases studied to a few scenarios of inestimable probability. The remainder of this paper surveys numerous contemporary studies that relate to the difficult problem at hand. Analyses reported in the literature are identified and discussed in terms of their individual capabilities and limitations. Methods in the literature generally are still very specialized either in terms of heat transfer mechanisms considered or geometry restrictions. Difficulties associated with their assembly into coupled heat transfer models are discussed.

Comprehensive modeling of very complicated and real systems of interest is, perhaps, unachievable. However, productive use of the most detailed analysis methods may benefit future PRA conducted in the manner of DPTRA as follows:

- Simpler MELTER-like modeling may be used in PRA to identify scenarios that contribute most to risk. These scenarios may be taken aside for more detailed analyses to verify (or adjust) response estimates.

- Detailed models may be constructed to study effects to be included more approximately in the high volume model. This approach is discussed further in the sections Modeling of Individual Transfer Modes and Modeling Applied to the Transport System.

Finally, the bottom line number developed in a PRA is primarily of interest as characterization of a low probability event of unacceptably high cost. It is widely held that 
the value of conducting PRA is realized not so much in the bottom line estimate as through its imposing of a systematic study of the handling and shipment methods and equipment. Procedural and equipment modifications may result from insights developed during such studies. The existing method (DPTRA) is important in identifying areas contributing significantly to the risk we take. Further development in thermal modeling detail is important to both improving the high volume thermal estimates (MELTER) and more detailed analysis of scenarios singled out for study. There is a need for model development in the middle ground.

The thermal modeling of a coupled system made up of a safe-secure trailer and its payload during the period of response to an external fire is a challenging task. All modes of heat transfer must be present in such a model (convection, conduction, and radiation) along with chemical reaction of some materials used in the construction of the trailer walls. Although the field of heat transfer analysis is often considered a "mature" technology, it is simply not the case that an accurate thermal model can be constructed for prediction of the transient heating of an internal payload within a structure exposed to an external fire.

It is clear that the field of heat transfer has progressed to the point that it is possible to handle many classical problems; i.e., a fixed regular geometry with known properties where one or possibly two modes of heat transfer are present. However, even when we can handle these problems, it is not obvious how well they reflect the behavior of real situations in which geometries are three-dimensional and irregular; boundaries are not aligned with gravitational body force vectors; properties are ill-defined; all modes of heat transfer interact; and the system is subject to transient and poorly known energy inputs. Such problems are intractable for various reasons, including a lack of understanding of the correct physics, lack of reliable property data, and to some degree a lack of computational capacity. The latter factor will probably be overcome before the others.

The analyst is faced with developing a model that is to some degree tractable while not straying too far from a reasonable approximation to the real situation. It is simply not possible to accurately model the real situation, as is pointed out in following sections. The degree to which a model reflects reality will always be open to question, and, at the present state of modeling capability, even a very "complete" model will be far from an accurate prediction of real system behavior.

In this report, the major factors affecting thermal modeling of the response of a payload to external fire are stated and examined; the effects that cannot be accurately modeled are discussed and the reasons for the inaccuracies are shown; and arguments are given for the ability to use "worst-case" analysis to model some of the less-well-defined phenomena. Some observations are given on the utility of worst-case analysis.

\section{The Model Considered}

The thermal model under consideration must represent a trailer and its payload exposed to a nearby pool fire. The objective is to predict the transient temperature history undergone by the payload following initiation of the pool fire. 
The model includes a specified flux or temperature onto one or more external surfaces of a rectangular parallelepiped. The specified flux or temperature on the outer trailer surface may be given, or may be computed from a model of radiative transfer from a nearby pool fire. The parallelepiped has the external dimensions of a safe-secure trailer. The parallelepiped is a shell, and the shell structure has various layers with thermal properties representative of various configurations of armor, insulation, and foam. The foam characteristics are such that it may begin a charring reaction when a certain reaction temperature is reached. The payload is of known geometry and location within the trailer, and has known thermal properties.

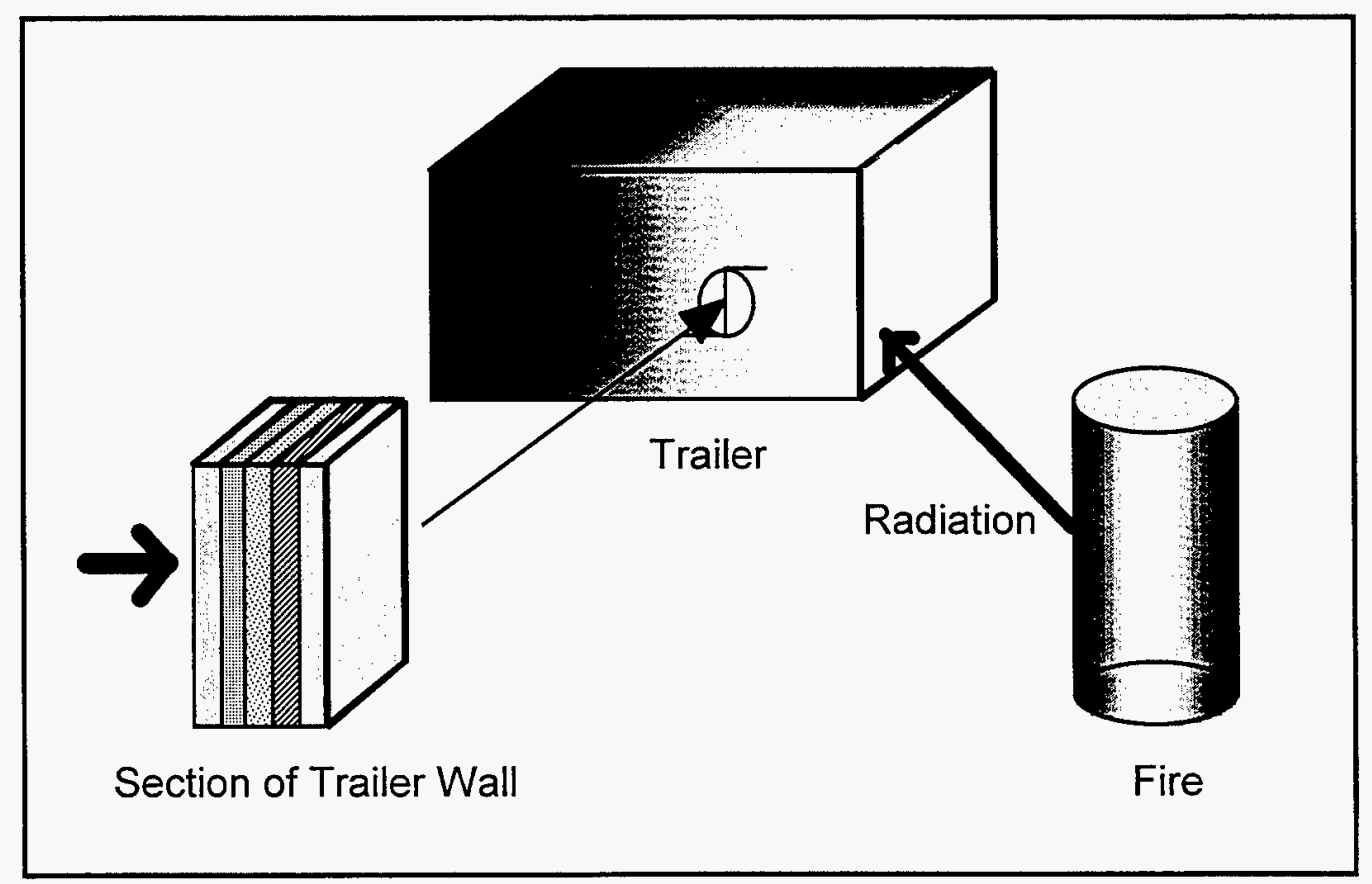

Figure 2: Schematic of Trailer, Fire, and Wall Section for Thermal Model

\section{Overall Modeling Considerations}

The prediction of the thermal response of a payload within a safe-secure trailer exposed to an external fire requires consideration of all significant modes of heat transfer, and each mode of heat transfer (conduction, convection, and radiation) is present in at least one part of the problem. Transient heating of the payload is affected by heat transfer by radiation and possibly convection from the external fire; transient conduction through the armored/insulated walls containing an internal charring layer; transient free convection and radiation from the internal surfaces of the trailer as they transfer heat to the payload; and the transient heating of the payload as affected by its thermal characteristics.

In this report, the factors affecting each of the individual modes of heat transfer (conduction, convection, and radiation) are first examined individually. The unknowns in modeling and the present state of the art in understanding the physics governing each mode are discussed with regard to thermal modeling of the safe-secure trailer. Following this, 
other factors that affect the modeling are examined and discussed, such as the coupling between heat transfer modes and its effect on prediction; the availability of necessary properties; the suitability of assumed boundary conditions for modeling; and the availability of experimental data for verification of the models. Finally, from the information available, the possibility and usefulness of developing simplified models based on worst-case assumptions are discussed.

\section{Modeling of Individual Heat Transfer Modes}

\section{Conduction}

Conduction heat transfer can be modeled quite well using conventional numerical methods. Commercial or internally developed codes based on either finite difference or finite element approaches can include all important effects such as anisotropic and temperature dependent properties, the presence of chemical heat release or other energy sources, the migration of material through the conducting matrix, etc. The chief difficulty in applying available modeling to complex problems is not the capability of the models, but the availability of accurate property values to insert in the model. For example, for a charring material, it is necessary to know the important physical properties (thermal conductivity, specific heat, and density) of the charring material prior to and following the charring reaction, as well as the parameters describing the amount of energy release or absorption due to the charring reaction. Although such properties can be estimated or measured, neither is an easy task. Uncharred material properties are often available from vendors or manufacturers, but such data is often given at a single temperature. Estimates of error in property values are rarely given.

The char reaction is initiated at a particular ignition temperature. Every arrangement of wall layers will affect the transient transmission of energy through the wall, and thus will affect the transient temperature experienced by the interior surface of the trailer. For example, if a layer of insulation is placed on the fire side of the char layer, ignition and charring will be retarded in time (case 1). If the insulation layer is instead placed between the charring layer and the interior surface of the trailer (case 2), the final interior temperature may be reduced below that experienced in case 1 . The best wall layer configuration may thus be different depending on the duration of the fire and the allowable interior surface temperature.

A simple one-dimensional charring wall model cannot account for lateral inhomogenieties in layer properties. If the char layer does not provide even charring, then some areas of the interior surface will experience faster transients than others. For example, local void formation has been observed during some charring tests. Further, formation of large volumes of gas during charring may cause structural damage of the uncharred foam or carrying off of the charred material, causing unanticipated thermal effects. A onedimensional model is also incapable of handling the effects of structural members, fasteners, or other non-homogeneous materials that are not perpendicular to the direction of conduction. Although modeling of such two and three dimensional effects is not in principle difficult, obtaining reliable property data on inhomogeneous effects is probably 
not feasible. Thus, reliable prediction of these multidimensional effects, while possible in principle, is probably not obtainable in practice.

\section{Convection}

\section{Steady state free convection}

A large body of recent research on free convection has centered on understanding how and why the various observed free convective patterns develop within an enclosure with fixed boundary conditions and geometry. The formation of steady and unsteady convective cells within such enclosures, the dependence of the cell patterns on the history of the enclosure boundary conditions, and the importance of three-dimensional effects are reasonably well understood for simple enclosures (rectangular or square cross-sections, thin gaps, etc.). However, small perturbations in thermal boundary conditions, initial conditions, geometry, and gravitational vector can cause large changes in free-convective behavior, and accurate prediction of this behavior even at low Rayleigh numbers is still a major research area in CFD. Very high Rayleigh numbers (above $10^{9}$, implying the presence of turbulent flow) are nearly always present in cases of interest here, i.e., cases which result in sufficient heating to threaten the cargo.

In the case of the safe secure trailer exposed to an external fire, one or more internal surfaces of the trailer will undergo a transient temperature increase. Free convection patterns will develop, and heated air near these walls will carry energy away and deposit it on cooler surfaces within the trailer, including the surface of the payload. Because of the trailer dimensions and the magnitude of the expected surface temperatures that can develop in this situation, the governing dimensionless parameter, the Rayleigh number, will undergo changes in magnitude during the wall temperature transient from zero to greater than $10^{10}$. The magnitude of the Rayleigh number for a given steady state condition generally determines the structure of the free convection cells present in the enclosure, i.e., number of cells, rotation speed, rotation direction, etc. The coupling between the fluid flow and the heat transfer (i.e., between the momentum and energy equations) is nonlinear through the temperature dependence of the air density, and results in the bifurcation-tochaos cell structure progression typical of nonlinear systems.

Consider the case of a steady hot wall temperature. At low Rayleigh numbers present at near-ambient hot-wall temperatures, the free convective flow will be laminar. If the heated surface is not horizontal, flow is usually in the form of a single large rotating cell of air that rises near the hot surface and falls near cold surfaces. As Rayleigh number becomes larger, the cell structure may undergo a series of bifurcations, forming multiple cells. At some critical Rayleigh number, the flow will become chaotic, and the cell structure becomes indeterminate. The transition to chaotic behavior may be related to the onset of turbulent flow. The critical Rayleigh number for the onset of transition to chaotic flow depends on the enclosure geometry and the fluid properties as embodied in the Prandtl number.

Given the geometry of the enclosure, the fluid properties, and the value of the Rayleigh number, numerical analysis should be able to predict the flow characteristics and the heat 
transfer that is expected in the enclosure. Care must be taken to prescribe a numerical grid and numerical accuracy requirements that give sufficient resolution. For transient wall heating, the flow patterns may pass through a series of bifurcations before reaching a final steady configuration, and the final configuration is sensitive to the prescribed initial conditions. (The appendix of this report reviews some of the recent work on free convective flows in enclosures.)

\section{Transient free convective effects}

Because of the difficulties in numerical analysis of free convection at steady state mentioned in the preceding section, it is clear that an exact transient analysis of free convection in an enclosure subject to transient boundary temperatures is probably outside the present state of the art. Some time-accurate numerical analyses are being carried out on simple systems. The transient case has some significant differences from steady state analysis. The inertia of the air in the trailer is probably sufficient to cause a lag in the predicted velocities and heat transfer from the conditions that will finally develop at steady state at a given heated surface temperature. However, it is also clear that the development should pass through the difficult-to-analyze bifurcation-chaos states quite rapidly for the trailer-fire case, and enter into turbulent free convection quite quickly after the wall heating begins. This is demonstrated by examining Figure 3, which shows the temperature transient examined in Case 1 of the MELTER code (Larsen, 1994) and the corresponding instantaneous Rayleigh numbers. The Rayleigh number goes from essentially zero to greater than $10^{9}$ (turbulent flow) over a few seconds. The implication is that the flow will enter the turbulent regime shortly after the initiation of a realistic fire-induced transient in wall temperature, and detailed examination of the early history of the flow during the bifurcation-chaos transitions is unwarranted in this case. However, the case detailed above is for a very-high-heating-rate case, and cases with slower heating rates may still require detailed analysis. If the fire is displaced from the trailer, much lower rates will occur and the system may well pass through the region of bifurcation and chaos.

By limiting consideration to Rayleigh numbers in the turbulent range, many of the difficulties of predicting free convective transfer in the enclosure vanish. However, even for turbulent free convection, little information is available for the case of an arbitrary cavity orientation with transient changes in the boundary temperatures. It is possible to carry out full three-dimensional transient solutions for free convective flow in a cavity; however, solutions are dependent on many parameters, vary considerably with small changes in parameters (particularly orientation), and take very long computation times to reach convergence. Thus, detailed solution over a range of parameters of interest is not feasible at present, although such calculations may be possible in the foreseeable future. It may be possible now to choose a few cases and examine the transient solutions for comparison with a series of steady solutions generated for each boundary temperature condition experienced throughout the transient. If the solutions at given times in the transient compare well with steady solutions (i.e., the fluid inertial effects are negligible), then a pseudo-steady solution can be used to approximate the transient solution. This would make prediction much simpler if it proves to be the case. 


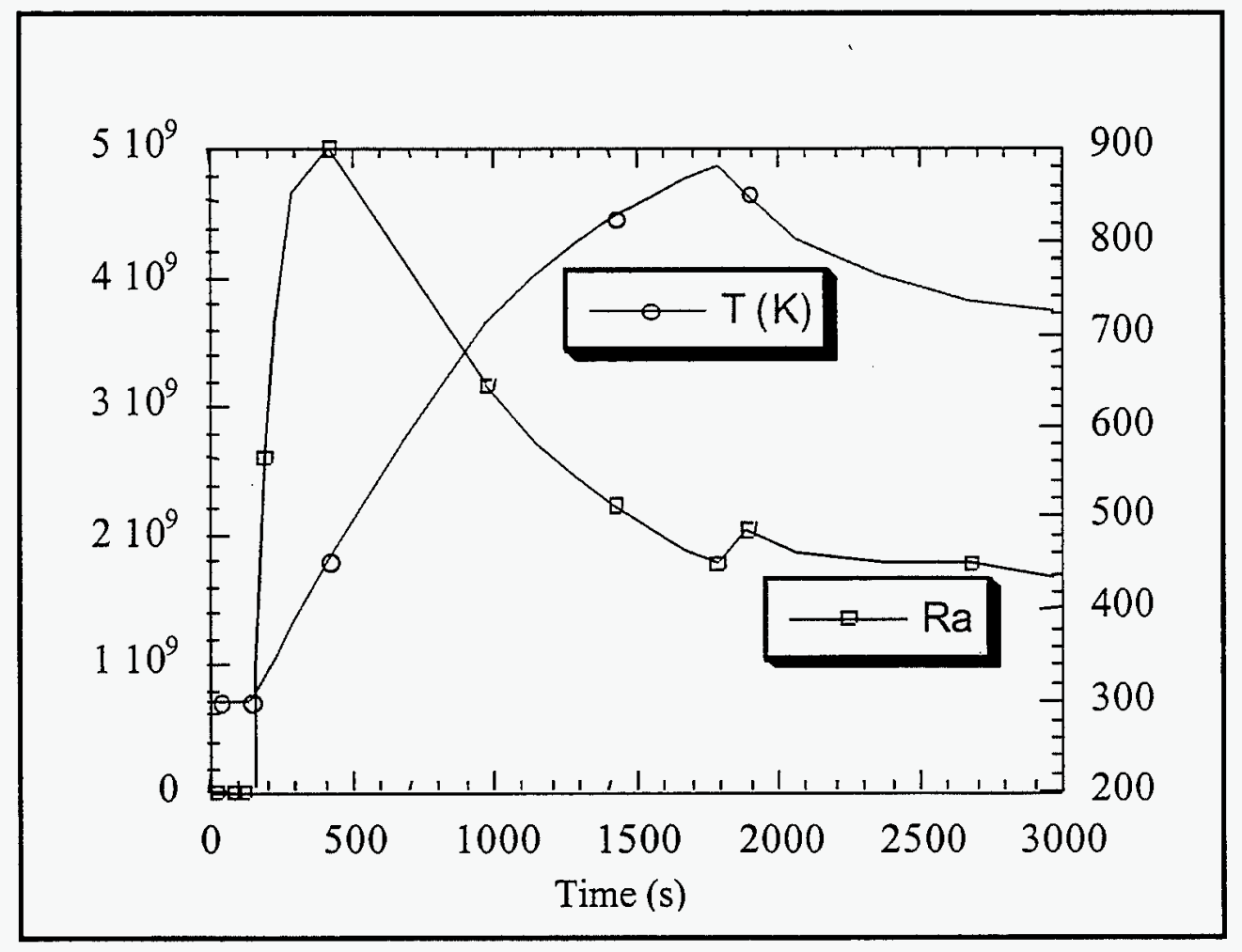

Figure 3: Instantaneous Rayleigh number development during typical surface temperature transients for the safe-secure trailer.

\section{Flow through apertures}

If the integrity of the enclosure boundary is lost because of a rupture of the trailer body, hot gases can flow from the external fire into the interior of the enclosure, especially if there is a wind transverse to the enclosure. There is some literature related to this case, although most of it was developed to study the effect of a fire inside an enclosure with an aperture (door or window), and thus does not directly simulate the case of an external trailer fire. Steckler et al. (1984), for example, computed orifice coefficients for flow through door and window openings from enclosures containing fires of various energy outputs, using an analytical study in comparison with full-scale fire experiments. More recently, Abib and Jaluria (1995) looked at the turbulent flow induced by a fire (intense local heat source) on the floor of a rectangular enclosure that was connected through an opening to a long corridor. They used a $k-\varepsilon$ turbulence model, and found reasonable agreement with some experimental data.

For horizontal vents that connect regions of differing densities, Cooper (1995) has presented an algorithm for predicting the flow between the two regions for the case when the density above the vent is greater than that below. The cases in which the pressure difference between the regions is positive or negative are included, so that combined buoyancy- and pressure-driven flows can be handled. This is the case expected for a trailer 
with a rupture in the floor and exposed to an external fire, but the buoyancy effect is opposite to that expected for a trailer with an aperture in the top exposed to an external fire. Cooper points out that simplified aperture flow relations based on aperture orifice coefficients can be greatly in error for these flows.

For an aperture in a horizontal plane (e.g., the case of a trailer with a hole in the floor or roof, or a trailer on its beam with a hole in the side), Singhal and Kumar (1995) among others have analyzed the rate of heat transfer due to free convection between a hot chamber below and a cold chamber above, with no cross-flow. Again, this is the case for a trailer with floor rupture, but is the opposite of the situation for a roof penetration, which will have heated air above and cold air below the aperture.

There is a also a considerable amount of work for convective flow through an aperture in a vertical wall [e.g., Steckler et al., 1984] for the case of a fire inside an enclosure with the aperture (window or door) connecting with a cold exterior. This is also the opposite of the trailer problem, where the hot gases are outside the enclosure and the cold air initially within.

Little work appears to have been done on the effect of a transverse wind velocity over the aperture in either case, nor on transverse aperture velocity effects on tilted geometries.

\section{Radiation}

Radiation is important to the problem at hand because it is probably the dominant mode of energy transfer from the fire to the trailer exterior. As the interior trailer wall increases in temperature, radiation also becomes the dominant mode of energy transfer from the interior surface to the payload.

\section{Modeling of radiation from a pool fire to the trailer.}

The complete modeling of the radiation from a pool fire is quite complex, as it requires knowledge of the shape of the flame envelope, and the temperature and soot distribution throughout the flame. These factors in turn depend on the reaction kinetics of the fuel and the details of soot production in the flame, and on the induced free convective flow and any influence of wind on the flame envelope shape. The free convective flow, radiative losses, and chemistry are coupled and must be solved simultaneously. If all of these factors are known (and many, in particular the soot production mechanisms and kinetics, are under active research and are not well characterized at present), then the radiative transfer equation can be solved for the radiant intensity incident on the trailer from the flame.

For a sooty diffusion flame typical of hydrocarbon pool fires, most of the radiation leaving the flame envelope originates near the envelope surface (i.e., the flame is optically thick), and the flame acts as a solid radiating blackbody at an effective surface temperature. If the flame is further taken to be isothermal and of known fixed shape (both of which require a considerable leap of faith), then the radiation from the flame to the trailer can be readily computed. For example, Guelzim et al. (1993) present radiation shape factors from tilted cylinders that are meant to approximate flames tilted by the wind. The results are in easy- 
to-use algebraic forms that reduce to known factors for vertical cylinders. Of course, in a real case, the shape of the pool fire plume is changing with time and is non-isothermal, and such a model, while convenient, will not reflect the real radiative transfer. To compute the radiation from the surface of a moving sooty nonisothermal flame to a tilted nonisothermal trailer surface is a formidable computational task. It can be done, but requires knowledge of transient flame shape, which in turn depends on a detailed calculation of combustion/free convection interactions, available fuel, and local wind conditions as affected by local terrain features.

Hayasaka et al. (1992) used a thermographic (IR camera) measurement of the radiation from a flame originating in a $2.7 \mathrm{~m}$ square pool of kerosene, and compared their measurements with simultaneous measurements using a radiometer. Agreement was quite good. They mapped the radiance of the flame (emitted intensity) at positions relative to the center of the pool surface. The maximum flame emission occurred from near the flame surface axis about $0.3 \mathrm{D}$ to $0.41 \mathrm{D}$ above the surface of the pool. This compares with $0.5 \mathrm{D}$ for heptane and $0.2 \mathrm{D}$ for crude oil reported by others. Assuming an optically thick black flame, they measured an effective flame radiating temperature of $1232-1448 \mathrm{~K}$ at the peak radiance point. For a detector placed at an $\mathrm{L} / \mathrm{D}$ from the flame of 5.0, they measured the irradiance (incident radiant flux) from the flame on the camera as being between 1.27 and $1.56 \mathrm{~kW} / \mathrm{m}^{2}$, which is near the value of 1.3 usually found.

Using uniform flame temperatures of $1200-1400 \mathrm{~K}$ and the flame size and geometry reported by Hayasaka et al. (1992) with the shape factor relations from Guelzim et al. (1993), an irradiance in the range of 1.36 to $5.23 \mathrm{~kW} / \mathrm{m}^{2}$ is found on a vertical element at an L/D of 5.0 from the base of the flame. These values would be expected to be too high, as they are based on the assumption that the uniform flame temperature used in the calculation is equal to the peak measured flame temperature. It is clear that a conservative radiative flux (i.e., too large) will be predicted by this method.

In the DPTRA study (Clauss, 1994) a distribution of temperatures that was independent of fire diameter was used to represent engulfing fires. For situations in which the SST was apart from the fire, the effective fire temperature was a function of fire diameter as described in the SFPE Handook for Fire Protection Engineering (Dinenno, 1988). The fire's emissive power, $E_{f}$, was taken to be:

$$
E_{f}=E_{m} e^{-S d}+E_{S}\left(1-e^{-S d}\right)
$$

where the emissive power of the luminous spots, $E_{m}$, was taken to be $140 \mathrm{~kW} / \mathrm{m}^{2}$, and that of the sooty spots, $E_{s}$ as $20 \mathrm{~kW} / \mathrm{m}^{2}$. These correspond to blackbody emitting temperatures of 1254 and $771 \mathrm{~K}$ respectively. The empirical coefficient, $S$, was taken as $0.12 \mathrm{~m}^{-1}$. For comparison with the $2.7 \mathrm{~m}$ square fire of Guelzim, et al., consider a circular fire of the same base area $\left(3.5 \mathrm{~m}\right.$ diameter) which suggests a fire surface radiance of $99 \mathrm{~kW} / \mathrm{m}^{2}$ or an effective blackbody radiating temperature of $1150 \mathrm{~K}$. Using MELTER's approximation of fires as right circular cylinders having a height to diameter ratio of 3 , the view factor to an element of area 5 diameters from the fire's base center is 0.033 , implying an irradiance at 
that point of $3.3 \mathrm{~kW} / \mathrm{m}^{2}$, which is consistent, but conservative, in the context of the preceding discussion.

\section{Radiation within the enclosure}

Within the enclosure, modeling of radiative transfer between the interior surface and the payload can be formulated to include all of the important factors, including wavelength and directional dependence of the surface properties. The limitation on accuracy here is again the lack of available properties to make such detailed modeling profitable. Usually, property values are available only as total (integrated averages over wavelength) and either hemispherical (integrated averages over direction) or normal (evaluated only in the direction normal to the surface). When this is the case, the analyst often reverts to simple modeling methods that assume the surfaces are gray (wavelength independent) and diffuse (have no directional dependence). It is possible to miss some important effects by using these assumptions, particularly if the boundaries are highly reflective and specular (mirrorlike), as may be partially the case for interior trailer walls of aluminum or stainless steel. In such a case, the radiation from the heated wall can be reflected from other interior surfaces to the payload, increasing the radiative transfer to the payload to above that expected by assuming diffuse surfaces. Surfaces tend to behave in a more specular fashion at the wavelengths typical of the major energy transfer at the temperatures important in the interior of the trailer (Modest, 1993; Siegel and Howell, 1992).

The modeling capability at hand today is applicable to steady-state systems with known geometry and boundary conditions. When transients are present, the surface properties, which are temperature dependent even for clean surfaces, will change with time in terms of spectral and directional characteristics. If the trailer structure is breached and soot or other products of the combustion are deposited on the surfaces, then the surface properties cannot be characterized except by assuming limiting values.

Conventional enclosure analysis is well developed, with commercial codes available to compute the necessary geometric shape factors and to carry through the energy exchange calculations for known-surface-temperature boundaries. These methods can be found in standard textbooks (Modest, 1993; Siegel and Howell, 1992).

\section{Modeling Applied to the Transport System}

\section{Wall Heating}

The outer surface of the enclosure is assumed to be heated through energy transfer from the nearby pool fire. Radiation will be the dominant mode, although it may be augmented by convection if the fire is close enough to the trailer that direct impingement of combustion gases onto the trailer occurs, or if wind gusts carry these gases to the trailer. The orientation of the flame relative to the heated surface affects the radiative transfer to the outer surface. Clearly, no surface of the trailer will experience uniform energy flux or temperature except in extremely unusual circumstances, and any given portion of the outer surface may experience repeated heating and cooling transients as fire conditions change. 


\section{Effect of wall orientation}

The trailer outer surfaces can be in almost any orientation relative to the pool fire energy source, and this fact has a number of implications on modeling detail. For example, the nonuniformity in the outer surface conditions indicates that the surface boundary condition is two-dimensional in nature, as well as transient. A worst-case assumption on the outer trailer surface is simply that the outer surface reaches a maximum temperature immediately upon being exposed to the pool fire; clearly, this will cause the most rapid heating of the interior surface of the trailer. It is not so clear that this condition will necessarily cause the most rapid convective heating of the payload.

Using the worst case assumption will maximize the radiative transfer. This occurs because radiative transfer to the payload is driven chiefly by the internal surface temperatures of the trailer. However, the natural-convective transfer to the payload depends not only on the heat transfer from the heated surface to the convecting medium (air) and then to the payload, but on the fluid mechanical development of the convective flow patterns within the trailer. It is not at all clear whether a non-uniform temperature distribution across some tilted trailer surfaces might induce a more rapid development of the convective flow pattern than a uniform maximum temperature imposed on the same surfaces, as some temperature patterns tend to stabilize rather than induce flow. It may then be possible to find a case in which convective transfer to the payload exceeds that predicted by the "worst case" maximum temperature isothermal surface assumption. However, because radiative transfer generally predominates, it is very unlikely that the total energy transfer to the payload could exceed the worst-case assumption even if such a fluid-mechanical anomaly were found to exist.

\section{Effect of Radiation/Convection Coupling to Transient Conditions on Internal Trailer Surface.}

As radiation is conducted through the trailer wall assembly, the interior heated surface temperature depends on the energy boundary condition imposed on the interior trailer surface. The more efficiently energy is removed from the interior surface, the lower will be the predicted interior surface temperature. Both radiation and natural convection are removing energy, and the predicted interior surface temperature will be lower than if either of these modes is considered independently. Thus, considering coupled heat transfer will predict heated wall surface temperatures that will be lower at all times than if either mode is neglected.

It will always be conservative to apply, for example, only the radiative transfer boundary condition to the heated wall while neglecting convective losses from the interior surface. This will make the predicted wall temperature above the actual value, which in turn will overpredict the radiative transfer as well as the natural convective transfer from the surface to the payload, as both modes of heat transfer depend on differences between the wall temperature and the lower payload temperature. This approach does not imply that either convection or radiation transfer should be neglected; only that the boundary temperature can conservatively be computed by neglecting one or both of these modes. The radiative 
and convective transfer can then be computed using the conservative boundary temperature. This approach has the added benefit that it uncouples the ignored mode from the boundary temperature calculation, considerably simplifying that calculation. For example, the interior wall temperature $T^{*}(t)$ at all times $t$ could be computed assuming that only radiative losses from the interior surface were important. Convective transfer from the interior surface to the payload would then be calculated based on the known surface temperature $T^{*}(t)$. The difficult free-convection calculation is thus uncoupled from the calculation of the trailer interior surface temperature, while maintaining a conservative (too large) prediction of heat transfer to the payload.

When wall heating ends (the exterior fire dies out or is extinguished), the wall temperature will peak and begin to decline. The interior wall peak temperature may occur after the exterior fire heating ends, depending on the wall heat capacity and construction. Payload heating will continue, however, as long as the interior surface temperature exceeds that of the payload. In this case, the calculation of interior wall temperature by neglecting the convective transfer will still be conservative, as the predicted interior temperature at any time will be too large. The predicted heat transfer by both radiation and convection will be overpredicted if based on this temperature.

\section{Specification of Boundary Conditions}

As noted under the preceding section, the heat flux and temperature distributions on the outer trailer surface will not be uniform. Imposing realistic thermal boundary conditions on the exterior of the trailer depends on a knowledge of the pool fire location, geometry, temperature distribution, and radiating characteristics; the trailer orientation relative to the pool fire and the trailer radiative properties; and local meteorological conditions of wind velocity and direction and air temperature. Knowing all of these factors, it is possible to use a combined radiative analysis with an analysis of flow over a three-dimensional body at arbitrary orientation to determine the energy distribution expected on the exterior of the trailer. The surface temperature and heat flux will also be affected by the energy transfer from the outer surface through the trailer shell to the trailer interior. Thus, the entire pool fire-trailer-payload problem becomes coupled, requiring a simultaneous solution of the entire system.

Such an approach is impractical, because it is on the limit of the state of the art for the external convective transfer analysis, reliable property data is not available, and the detailed analysis would have to be run for every individual case to be examined.

Each factor could be varied parametrically to determine its effect, and some factors can examined for their effect without carrying through a complete analysis. This approach would perhaps allow some of the parameters to be eliminated as being unimportant to the overall analysis.

To achieve reasonable modeling accuracy within computation resources, it appears necessary at present to fall back on some worst-case assumptions for the trailer surface boundary conditions. 


\section{Effects of flame tilt, size, location}

If it is assumed that convective effects (wind-induced impingement of combustion gases) are not present, then a uniform temperature can be imposed on external trailer surfaces exposed to radiation from the pool fire. The imposed temperature will still be dependent on the orientation and distance of the trailer from the fire. Even for this simplified case, the implication is that resulting temperatures on the interior surfaces of the trailer will be individually uniform. As shown previously, the Rayleigh numbers on for internal surfaces very rapidly approach those typically of turbulent free convection; however, for an arbitrarily tilted rectangular (three-dimensional) cavity with one or more heated surfaces, the ability to predict free-convective transfer is marginal. Thus, even for simplified boundary conditions (constant temperature on each external trailer surface), complete solution of the energy transfer to the payload is not possible today with confidence.

\section{Coupling to Object}

Some experimental work is available for the heat transfer between the enclosure interior surface and a body within the enclosure. All of this work is for a heated body transferring energy to the enclosure surface, which is the opposite of the case for the trailer fire.

Warrington and Crupper (1981) measured the heat transfer from four heated isothermal parallel tubes in a square array to the isothermal cooled walls of a cubical enclosure. Fluids in the enclosure were glycerin, air, water, and silicone. Measurements were done for both a horizontal and a vertical tube array. Various rotation angles of the array were examined. Little effect was noted for rotation angles around axis of the vertical array, but significant orientation effects were noted for the horizontal array; heat transfer was considerably greater for the horizontal configuration.

Zhao et al. (1992) performed numerical analysis and experiments for the case of radiation and free convection to air from three electrically heated parallel cylinders on the floor of a rectangular enclosure. The external surfaces of the enclosure were cooled by free convection, and conduction through the walls was considered. The geometry was essentially 2-D (the L/D of the cylinders was about 14). The flow profiles in the enclosure and the heat transfer characteristics were significantly affected by the presence of the cylinders and by their spacing from the center cylinder.

Keyhani and Dalton (1996) studied heat transfer from an $N \times N$ array of rods to an isothermal square enclosure surface for $N=3,5$, and 7 . They present a correlation for modified Nusselt number vs. modified Rayleigh number that includes free convection, conduction, and radiation transfer.

These references all have common boundary conditions of a known heat flux on the rods and a fixed uniform temperature or an external convective loss on the entire enclosure surface. 


\section{Effect of payload characteristics (shape, composition, properties, configuration of layers)}

Heat transfer will occur between the warmer surfaces of the trailer interior and the payload by combined radiation and free convection. Conductive transfer could also occur from heated surfaces through mounting fixtures that hold the payload in place, but this transfer can be minimized by design of the fixtures to include thermally insulating components.

If the payload has significant thermal capacity, then the payload temperature will lag the transient interior temperatures of the enclosure (trailer). The presence of this heat sink will in turn lower the predicted enclosure surface temperature, causing a difference in the predicted transient temperatures throughout the system of the trailer wall, interior surface, and payload. This coupling between the payload and the enclosure can be completely modeled if the payload internal thermal characteristics are known. Such modeling will require knowledge of the payload surface geometry, surface emissivity and absorptivity, as well as specification of the internal components and their individual geometries, specific heats, thermal conductivities, and connectivity to adjacent components.

A conservative model of payload thermal behavior can be envisioned by simply holding the payload temperature at its initial value throughout the temperature transient. This will impose the maximum temperature difference between the interior trailer surface and the payload at all times, and this will in turn impose a conservative (too large) heat flux on the surface of the payload. If a complete model of the interior thermal characteristics of the payload were available, then this transient surface heat flux could be provided as an input to such a model, and the detailed (but conservative) transient temperatures throughout the payload could be predicted.

\section{Magnitude of retardation of heat transfer due to radiative/free convective coupling} In certain situations, radiation can enhance free convection effects. In the work of Zhao et al. (1992) for heated horizontal cylinders described above, radiation was found to significantly affect both the temperature and the flow field in the enclosure. It was found to even out temperature variations and to provide better cooling of the heated cylinders on the enclosure floor.

In the trailer case, radiation from the heated interior surfaces will tend to heat adjacent trailer surfaces, which will reduce the driving force for development of free convection from that predicted by neglecting radiation in most cases. Similarly, free convective transfer from the hotter to colder surfaces will tend to even out temperature differences, thus reducing radiative transfer calculated by neglecting free convection. Clearly, consideration of coupling will reduce heat transfer from either mode considered individually.

\section{Retardation due to geometry/location of object (flow restriction)}

Depending upon the size, shape, and location of the payload and its attachment fixtures, free convection patterns may be considerably disrupted when compared with the cases 
usually studied in the literature. Tripping of the flow patterns into multi-cell patterns can be imagined in the low Rayleigh number regime. Such flow changes will alter the predicted heat transfer, and will generally reduce the heat transfer calculated by neglecting such disruptions, since velocities will be reduced resulting in lower heat transfer coefficients between the fluid and surfaces.

\section{Effects on radiative transfer of coupling to free convection}

Yang (1986) reviews the interactions associated with the strong coupling between free convection and radiation for the case when the convecting fluid participates in the radiative transfer. For a trailer that has not been ruptured, the medium inside the trailer (air) will be transparent to radiation, and the effects due to a participating medium will not be important. Should the trailer be ruptured, smoke and combustion products may enter the trailer, and participating media effects may then be significant. The accurate treatment of this class of energy transfer problem is a major contemporary research area. In the practical trailer problem, which requires treatment of wavelength dependence and anisotropic scattering (which is in turn dependent on smoke and combustion product concentration, distribution, and temperature), it is probably not possible to achieve accurate solution at this time.

There has been some useful work for the transparent gas (air) problem suitable for the unruptured trailer analysis. de Groh and Kassemi (1993) examine the case of a top-heated rectangular enclosure, usually considered to be stable-stratified to free convection. However, when radiation from the top surface to the adiabatic side walls is considered, the zero-flux boundary conditions at the vertical walls requires the wall temperature to increase when radiative transfer occurs, inducing the onset of free convection. Free convection within the cavity was also induced when the vertical walls were cooled by external free convection. Experimental and numerical predictions for this situation were in good agreement. They showed that radiation was important even at heated top surface temperatures as low as $300^{\circ} \mathrm{C}$ when the cooled bottom plate was maintained at $30^{\circ} \mathrm{C}$. If radiation were neglected in the numerical analysis, very poor prediction was noted.

Balaji and Venkateshan (1994) examined the effect of combined surface radiation and laminar free convection in the standard problem, described in the appendix, for $0.05<A<0.5$ (where $A$ is the aspect ratio $W / H$ ), $0.2<\operatorname{Pr}<20,10^{3}<R a_{W}<10^{6}$, $0.6<\left(T_{C} / T_{H}\right)<0.9$. They examined a large range of emissivities on the heated and cooled surfaces (with equal emissivities) and on the adiabatic surfaces (with equal emissivities, but different from the heated/cooled surfaces). The adiabatic condition was applied independently to radiation and convection (i.e., it was not assumed that the sum of the radiation and convection heat flux was adiabatic). In this case, the convective and radiative heat transfer are uncoupled because the radiative adiabatic wall temperature distribution falls out of the radiative calculation (although it is not clear that the authors realized this), so the calculation of the combined heat transfer is quite straightforward. A simple correlation equation for the radiative transfer alone from the hot to the cold plate was generated by numerically solving for the radiative transfer for many cases and curve-fitting the results: 


$$
N u_{R}=q_{r a d} / \sigma T_{H}^{4}=0.966\left[\left(2 / \varepsilon_{H}\right)-1\right]^{-0.957}\left(\left[1-\left(T_{c} / T_{H}\right)^{4}\right]^{1.042}\left[\left(\frac{1}{A}\right)+1\right]^{-0.129}\right.
$$

If $A=W / H \rightarrow \infty$ (infinite parallel plates), then the result approaches the known analytical result for that case:

$$
N u_{R}=\left(\left[1-\left(T_{c} / T_{H}\right)^{4}\right] /\left[\left(2 / \varepsilon_{H}\right)-1\right]\right.
$$

Because the radiation is uncoupled for the imposed boundary condition, the radiative transfer result should apply regardless of whether the flow is laminar or turbulent.

An enclosure heated on one side by radiation that enters through the opposite vertical transparent wall was studied experimentally by Webb and Viskanta (1987). They considered the case of an absorbing fluid (water, which is highly absorbing in the IR and transparent in the visible portion of the spectrum), and found good agreement with numerical predictions, although there was some difficulty with matching of grid requirements for radiation transfer and the free convective calculation.

\section{Effects on Radiative Transfer of Coupling to the Payload}

When coupling between the interior surface and the payload is included in a thermal analysis, the temperature of the enclosure surface will be reduced throughout the transient, and the payload temperature will be increased because of the heat transfer. Thus, the temperature difference between the interior surface and the payload will be lower at each time increment.

If the heat transfer is considered as a simple addition of convective and radiative transfer, then the predicted total heat transfer will always exceed the value found for the more accurate coupled case. Radiative heat transfer to the payload can thus be conservatively predicted by calculating the surface temperature of the trailer and the payload temperature while ignoring the effect of free convection; free convective effects can then be computed using the temperatures found in the radiative calculation. The sum of the radiative plus convective heat transfer will then always be too large, providing conservative design estimates.

Rao et al. (1997) have investigated the effect of radiation-free convection interactions in a right-angle corner, comparing experiment and numerical analysis. They examined the effect of surface emissivity, vertical surface height, and base temperature on the relative amounts of radiative and convective transfer, and give correlation equations for both total and radiative transfer. 


\section{Validation and Verification}

Because of the complexity of the physics in the problem of payload heating, experimental validation of the model is necessary at some level. Complete validation by study of an actual payload exposed to a real pool fire is very expensive, and may not produce the required validation in any case.

Detailed large scale experiments are expensive and subject to many uncontrollable and/or unmeasureable factors. These include wind direction and velocity during the test and the resulting effects on pool fire shape and size and possible flame impingement on the exterior of the trailer; and the difficulty of controlling the construction details of the trailer from test to test. In addition, the limitations of testing due to time and cost to a few cases may not show the sensitivity to important factors such as orientation of a partially overturned trailer.

If test and model do not agree, then it may be very difficult to tell whether the differences are due to experimental errors, omission or inadequate modeling of important effects in the thermal model, or lack of accurate thermophysical property data in the model.

It may be possible to carry out small-scale experiments to partially validate the model; however, the problem is very nonlinear with both temperature and geometry, and the confidence in scaling of such experiments to the full problem will not be not high.

Perhaps the most fruitful experiments will be the determination of accurate thermophysical and transport properties for use in the thermal model. Without these, there will always be uncertainties in the predictions, and an inability to compare the physics of the model and its predictions with either small- or full-scale experiments.

Verification of a code refers to extensive testing to make sure that the code has no internal coding errors or errors in analysis. Verification can never be fully assured, but a code can (and should) be checked against known limiting solutions and cases solved by other methods.

A numerical verification should be invoked to see whether pseudo-steady solutions compare well with full transient results for a sufficient range of cases to determine if such solutions are accurate. If pseudo-steady solutions found by assuming that the freeconvective flow characteristics at any time are similar to those that would be found for steady conditions at that time, so that inertial effects during the transient can be neglected, it will considerably simplify modeling of free convection.

\section{Worst-Case Analysis}

Based on the observations of the physics of energy transfer between the external pool fire and the payload inside the safe-secure trailer, it is possible to examine the feasibility of employing a worst-case analysis for design purposes. Care must always be used in worstcase analysis; it is meant to answer a specific question, such as "will the payload exceed a given temperature in a given time or not?" Using such an analysis to compare the behavior of system A with that of system B is dangerous, because the worst case assumptions may not apply to both systems in the same way. Attempting to answer the question "is system A 
safer than system B" by using a worst-case analysis on each and finding that system A will take longer to reach a critical temperature than system $\mathrm{B}$, and thus answering the question with a "yes" is not warranted. The worst case analysis on system B may have been made with different constraints than on $\mathrm{A}$, and if a more detailed analysis is performed, it may be found that $B$ is a better choice. This does not negate the value of worst-case analysis, but it does mean that such analysis must only be applied to the particular question being asked.

\section{Ability to Truly be Conservative in All Issues}

Because of the complexities of payload/trailer geometry, pool fire characteristics, property variations, etc., it may be that treating each issue conservatively will lead to such an overprediction of thermal effects that a meaningless design will result. Considerable care will be necessary to determine minimally conservative assumptions that bound the physics of the problem, without producing useless results. Certain factors must be examined quite carefully, and some of these are examined below.

\section{Minimum dimensions (1-D, 2-D, 3-D) necessary for accurate modeling and for WCA modeling}

Computational speed for numerical heat transfer models, particularly those involving radiative transfer, is very sensitive to the dimensionality of the problem. Calculation time often is related geometrically to the problem dimensionality, and three-dimensional problems are often computationally intensive. Depending on the degree of coupling treated in the problem, convergence of the highly non-linear equations can be a serious difficulty that grows worse for multidimensional problems. If a one-dimensional approach can be shown a priori to be conservative compared with more rigorous treatments, then it may well be justified.

Radiative transfer can be made to be conservative through a one-dimensional approximation by assuming that the payload is surrounded by a radiative source at the highest interior trailer surface temperature. Any multi-dimensional enclosure will have some lower-temperature surfaces, and will thus provide lower energy transfer to the payload than for the one-dimensional approximation.

For free convection inside the trailer, it is probably necessary to carry through at least a two-dimensional solution to approximate the flow field that will develop. The presence of end walls in a three-dimensional analysis of the trailer will often reduce the predicted twodimensional convective transfer by providing additional flow resistance to the thermallyinduced free convection. As noted in the section on free convection, however, if multiple surfaces in a tilted trailer are exposed to the external pool fire, then it is not clear whether a two-dimensional solution can be envisioned and solved that will remain conservative. However, it may well be possible to show that free convective transfer remains small compared with radiation, and that a relatively simple solution for free convection will suffice. 


\section{Potential off-the-shelf correlations for use in worst-case analysis}

Many correlations are available in the literature that can be used to predict the mean flow velocity that will develop in an empty (no payload) enclosure due to free convection by heat transfer to the boundaries. As this velocity will be reduced by the flow restriction caused by the presence of the payload, it should be a conservative (too large) value. The computed velocity can be used to define the value of the Reynolds number for flow over the payload, and again the predicted value will be too large as it is based on a too-large velocity. Correlations of Nusselt number versus Reynolds number can then be used to predict the heat transfer coefficient between the payload and the flow field, and the value so produced will again be too large, as all such correlations predict that Nusselt number increases with increasing Reynolds number. This approach to predicting heat transfer to the payload relies on a large body of empirical data for forced convective transfer for, for example, cross-flow over cylinders or flow over spheres.

Correlations are also available for predicting the heat transfer between a heated or cooled body of arbitrary shape submerged in a quiescent fluid [ e.g., Hassani and Hollands (1989)]. If the fluid temperature is taken to be that of the heated interior surface of the trailer, the maximum possible fluid-to-payload temperature difference can then be used in predicting the heat transfer to the payload by convection. This approach could be used for cases where the trailer roof is heated, and free convective fluid motion does not develop because of the stable density gradient.

\section{Conclusions}

Based on the discussions in this report, it seems clear that a full thermal analysis of the payload heating due to an external pool fire is far too complex for complete, accurate, and confident solution.

However, predictions of behavior can be found with some confidence for an intact trailer, because

- for high heating rate cases (and these are of most interest), fully-developed turbulent free convection will develop very rapidly within the trailer at the onset of an external pool fire, avoiding the complexities of developing bifurcated/chaotic regimes typical of laminar flow and providing a conservative solution.

- Additive solutions for radiative plus convective heat transfer are conservative, and this considerably simplifies the analysis by allowing the heat transfer modes to be uncoupled and treated independently.

- Multi-dimensional analysis is probably not necessary, as one- and two-dimensional analysis is conservative provided that it can be shown that convective transfer is overshadowed by radiative transfer within the trailer.

If support of a PRA requires a very large ensemble of scenarios to be analyzed, tractable models that reliably find at least an approximate solution without case-by-case analyst intervention are needed. Limiting assumptions and approximations must be accepted to 
achieve this robustness. Assuming that conservative analysis predicts survival of the payload under prescribed pool-fire conditions, the problem is of course solved. If payload temperature prescriptions are exceeded, then a more careful analysis is desired. In sampling the whole scenario space it is expected that both thermal failure and survival will be predicted. The "skin" of the failure surface is made thick by the acceptance of conservative thermal modeling assumptions and the implication of greater risk must be accepted in the best available risk estimate. The goal of refining our analyses is to eliminate both false alarms and false safe predictions. Presently, we attempt to deal with the latter group at the expense of the first group by making conservative assumptions.

If the trailer armor is ruptured prior to the initiation of the pool fire, then it is probably impossible to provide a thermal analysis with any confidence, as direct radiation and convection coupling between the fire and the payload are possible. This situation is subject to so many variables as to preclude accurate analysis except on the basis of very stringent worst-case assumptions which almost certainly will predict that payload temperature limits can be exceeded. 


\section{APPENDIX : Review of Recent Research on Free Convection in Enclosures}

The number of publications on free convective transfer in rectangular 2-D and 3-D cavities is immense, and a very large amount of research continues to be published, Good reviews of the state of the art through their time of publication are given by Ostrach (1988) and Yang (1988).

It is difficult to obtain accurate solutions at large Rayleigh number because of the imperfect turbulence models that are available and the stiffness of the governing equations which cause difficulties in convergence to accurate solutions. At low Rayleigh numbers, the steady state behavior of the flow and heat transfer in such an enclosure has many uncertainties because of the sensitivity of the behavior to the history of approaching the steady state, particularly for cavities that are heated at the bottom surface. For these reasons, complete understanding of the development of free convection in some cases is quite incomplete. For example, if the Rayleigh number is initially small and then grows to a value that places the flow in the turbulent regime, uncertainties will be encountered in both the low and high Rayleigh number regions.

Here is presented a brief review of recent literature on free convection in rectangular geometries that gives a flavor of the state of the art, with comments about the remaining difficulties and uncertainties for the modeler.

\section{Laminar Free Convection}

\section{Two-Dimensional Solutions}

Papers on free convective flow patterns and heat transfer in square and rectangular enclosures continue to be published, often to demonstrate new computational techniques or to examine unusual boundary conditions and their effect on free convective transfer.

Bearing in mind the potential uncertainties because of the effect of history on some steady state solutions that are predicted by numerical analysis, some interesting solutions are nevertheless available.

\section{The standard problem}

The thermal configuration that has been studied the most is shown in Figure A-1. The left vertical surface 1 is heated, the right hand vertical surface is cooled, and the top and bottom are insulated. The aspect ratio is defined as $A=W / H$ (although some references use $H / W$.) In this section, some recent work on the standard problem is examined, and various extensions to the standard problem are seen to give some insight into the thermal design of a Safe Secure Trailer. 


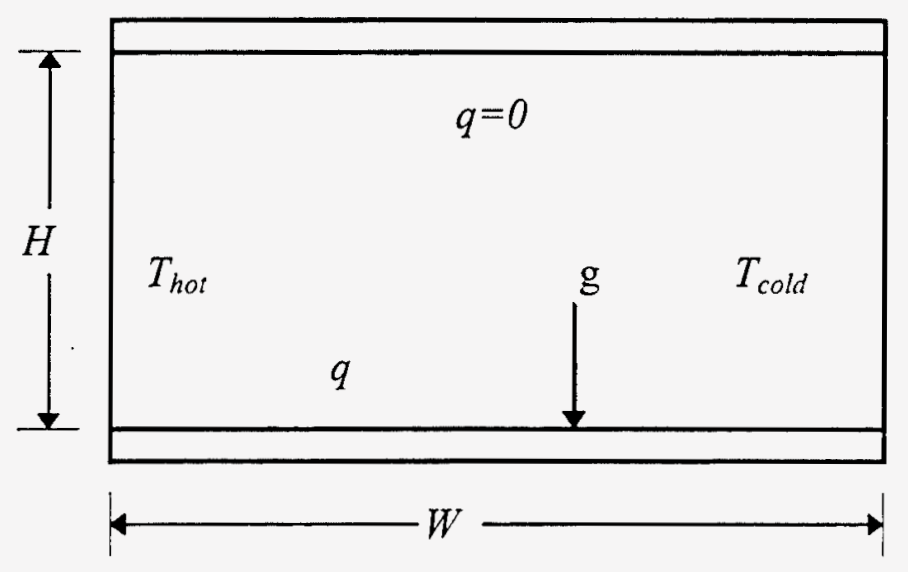

\section{Figure A-1: Standard Two-Dimensional Enclosure and Boundary Conditions for Free Convection}

De Vahl Davis (1983) has presented the benchmark solution to the standard problem, and most contemporary solutions refer to this paper for comparison of new methods or to examine the effect of changes in boundary conditions or other factors on the benchmark solutions. Kuo (1996), for example, examines both finite volume methods and spectral methods applied to the standard problem, and finds agreement with de Vahl Davis' solutions within about 0.3 percent for maximum and average Nusselt number for $10^{4}<R a<$ $10^{6}$.

LeQuére and Alziary de Roquefort (1988) examine the standard problem (Fig. A-1), and then compare the case of conducting horizontal walls on the results for the standard problem with adiabatic horizontal walls. They report major changes in the critical Rayleigh number for transition to unsteady conditions for aspect ratios near 1 (they studied aspect ratios in the range 0.1 to 1 ).

Fang and Paraschivoiu (1992) compared numerical methods and boundary condition transformations for flow in a square standard enclosure, and obtain solutions for air for $10^{3}$ $<R a_{H}<10^{6}$ that agree well with the benchmark solution of de Vahl Davis (1983).

Henkes and Hoogendoorn (1993) examined the asymptotic behavior at large Rayleigh number for free convective steady laminar flow in the standard problem, and showed the scaling parameters that should be used for wall heat flux, vertical velocity, boundary layer thickness, and horizontal core-region velocity.

Daniels and Wang (1994) examined the behavior of the standard cavity in the limiting case of $A \ll<1$ (very tall cavities), and also examined this case when the horizontal boundaries are perfectly conducting. A combination of numerical and analytical techniques was used. 
They present average Nusselt numbers for the hot wall for $R a_{W}<7 \times 10^{4}$ for $P r=0.733$ in the adiabatic case, and for $500<R a_{W}<9000$ in the conducting case. In a follow-on study [Wang and Daniels (1994)], they examine the case of $A \gg 1$ (a very shallow cavity) with perfectly conducting horizontal walls, and present average cold-wall Nusselt numbers for air for $500<R a_{H}<14,000$.

Lykoudas (1995) used various approximations for limiting cases to develop a predictive equation for the Nusselt number for a standard enclosure in terms of $A \times R a_{W}$ in the range $10^{3}<A \times R a_{W}<\sim 10^{7}$, and showed good agreement with experimental data.

Xia et al. (1995) studied the effect of imposed periodic hot wall temperature variations in the standard problem for air in a square enclosure. Parameters varied were the amplitude of the oscillation and the Rayleigh number. The imposed oscillations were of the same order as the natural frequency of the system, and they found that transitions between cell regimes were induced at lower Rayleigh numbers than for steady boundary conditions.

\section{Bottom heated cavities}

Yang and Mukutmoni (1993) have shown that the numerical solution of this class of problems is extremely sensitive to the prescribed initial conditions and the history of the flow development. For a given Rayleigh number and other fixed conditions, multiple solutions for the cell structure and heat transfer may exist both physically and numerically; thus, straightforward numerical analysis may predict a possible solution, but one which, based on experimental observation, is unlikely. At the given state of the art, it is not possible to accurately predict the free convective heat transfer in a particular enclosure at fixed conditions when the system has a Rayleigh number within the range of the bifurcation sequence up to chaos. Yang and Mukutmoni (1993) recommend a careful program of experimental observation coupled with numerical analysis to assure that the correct doubling sequence is being predicted in reaching the conditions under study. They have had success using this approach in predicting the behavior of free convective heat transfer in a horizontal rectangular enclosure heated from below (typical of a trailer with a fire under the floor). However, this is clearly an impractical approach for analysis of general safe secure trailer thermal effects. Lacking such experimental confirmation, many of the steady-state solutions available in the literature are open to question.

Ruhul Amin (1993a,b) also studied a bottom-heated cavity. In the first paper, a cavity with heated bottom, adiabatic left and top surfaces, and isothermal cold right hand wall is was analyzed, and then the effect of adding large-scale roughness elements on the bottom surface was compared. Air was the fluid, and results for aspect ratios from 1 to 4 and $10^{2}<$ $R a_{H}<10^{5}$ were presented. Comparisons were made to equal-volume enclosures with rectangular roughness elements on the bottom surface that had hot horizontal surfaces and adiabatic vertical surfaces. Increases in Nusselt number of $78 \%$ were observed for low Rayleigh number $\left(10^{2}\right)$ at aspect ratio of 4.0 when the roughness period was one-half the cavity width. Ratios of Rayleigh number with roughness to Rayleigh number without roughness of less than 1.78 or even less than unity were observed for other values of the parameters. In Ruhul Amin (1993b), a similar study was carried through except that the top 
wall was cooled, and both side walls were adiabatic. Maximum enhancement of heat transfer was 57 percent for these boundary conditions, and occurred at $R a_{H}=2 \times 10^{3}$ for a particular set of roughness amplitude and period. A decrease in heat transfer of 61 percent compared with the smooth-wall case was observed at $R a_{H}=3 \times 10^{4}$; this was because of the onset of a four-cell configuration induced by the roughness.

When the bottom surface is only partially heated and another portion is adiabatic, considerable influence on the free convective heat transfer has been observed. Zia et al. (1990) numerically analyzed the effect of a local heat source placed at the center of the adiabatic bottom surface in a square enclosure with hot left hand wall, cold right hand wall, and insulated top. The magnitude of the heat source was varied, and it was found that the hot wall Nusselt number decreased and the cold wall Nusselt number increased as the source intensity was increased. The standard Rayleigh number was in the range $10^{3}<R a_{H}<10^{6}$ for air. Hasnaoui et al. (1992) treated enclosures with a portion of the bottom heated, adiabatic side walls, and cooled top. They varied Rayleigh number from 0 to $5 \times 10^{6}$, aspect ratio from 1 to 2 , the location and relative size of the hot isothermal portion of the bottom surface, and the Prandtl number. They observed multiple steady state, periodic, and aperiodic numerical solutions that depended on the initial perturbations imposed on the system, and noted that imposing symmetry when the heat source was located symmetrically on the lower wall precluded observing the multiple steady and periodic solutions, which are inherently unsymmetric. Nicolas and Nansteel (1993) present experimental results for a square enclosure with partially heated constant flux bottom surface, insulated left side and top, and cooled right-hand vertical surface using water. They varied the relative width of the heated surface, and varied Rayleigh number in the range of $7.29 \times 10^{10}$ to $3.69 \times 10^{11}( \pm 5 \%)$. They observed some cell structures that had not been predicted by earlier numerical analysis of the problem.

Ganzarolli and Milanez (1995) investigated the flow and heat transfer in a rectangular cavity by numerical analysis for the case of constant temperature or uniform heat flux on the bottom surface, symmetrically cooled sidewalls and insulated top. For the range of parameters of $10^{3}<R a_{H}<10^{7}, \operatorname{Pr}=0.7$ and 7 , and for shallow cavities with aspect ratios from 1 to 9 , they found that only a single cell formed and no bifurcation sequence occurred.

Wakitani (1997) investigated deep cavities $(A=1 / 16)$ with differentially heated sidewalls, and observed the numerical prediction of cell formation by either slowly increasing the value of $R a_{W}$, or by imposing an impulsive $\Delta T$ on the system and observing the time dependent behavior until steady conditions were reached. A definite hysterisis was observed in the sequence of cell patterns in the range $8 \times 10^{3}<R a_{W}<5 \times 10^{4}$, with the observed pattern at a given value of $R a_{W}$ in this range depending on the initial condition and whether the pattern was approached through increasing or decreasing $R a_{W}$. Above $R a_{W}=5 \times 10^{4}$, the observed pattern was independent of initial condition. 
Shallow differentially-heated cavities $(A>4)$ were examined by Boehrer (1997), who indicates that the available data and predictions for these cavities can be divided into three flow regions. These are flows that are limited to layers near the boundaries (governed by conduction), a transition region, and convective flows which cause rotation of the entire fluid mass. Limitation is to cases with $R a_{H}<A^{12}$ and $\operatorname{Pr}>1$. The governing parameters for the region boundaries was found to be $R a_{H} / A=10^{2}$ and $R a_{H} / A=10^{4}$.

\section{Tilted cavities}

Tilted cavities of course present additional computational difficulties to the standard free convection problem, but are of interest for the problem at hand as they simulate to some extent a truck body involved in an accident involving partial overturning.

Kuyper et al. (1993) examine free convection of air for a square cavity over Rayleigh numbers that cover both laminar and turbulent flow $\left(10^{4}\right.$ to $\left.10^{11}\right)$ for cavity inclinations of $0^{\circ}$ (heated from below) to $180^{\circ}$ (heated from above). The connecting walls are adiabatic. They found that, as previously proposed, flow at $R a_{H}=10^{6}$ is stable with a single cell for all tilt angles greater than $20^{\circ}$, but the solutions become unstable and difficult to converge for the heated-from-below configuration (tilt $<20^{\circ}$ ). Discussion of the turbulent flow results is left to that section.

Soong et al. (1996) also examine transition and hysteresis in tilted enclosures with air for tilt angles from 0 to $90^{\circ}$, Rayleigh numbers $\mathrm{Ra}_{\mathrm{H}}$ from $1 \times 10^{3}$ to $2 \times 10^{4}$, and aspect ratios of 4,3 , and 1 . Maps of the cell structure for various tilt angle and Rayleigh number are presented for aspect ratio of 4 , and large hysteresis effects are observed in the maps for $R a_{H}$ $>2000$, with results in steady state depending on whether the state is approached by increasing or decreasing tilt angle.

Kangni et al. (1995) treat inclined enclosures with multiple partitions connected to opposite adiabatic surfaces, with air between the partitions. Heated and cooled isothermal boundaries were parallel with the partitions. Overall enclosure aspect ratios from 0.05 to 1 , tilt angles for 0 to $180^{\circ}, 10^{3}<R a_{W W}<10^{7}$, partition-to-fluid conductivity ratios from 1 to $10^{4}$, and various numbers, thicknesses, and spacings of partitions were examined. This study was carried out to understand the behavior of solar collectors, but has some interest for wall structures with internal baffles. All results showed that convective transfer was reduced as partitions were added, and a maximum was reached in Nusselt number at tilt angles of $60^{\circ}$ to $90^{\circ}$, depending on the particular values used for the other parameters.

Showole and Tarasuk (1993) treat the case of free convective transfer to air in an opentopped tilted cavity with all three surfaces heated. Numerical results are compared with experiment for tilt angles of $0,30^{\circ}, 45^{\circ}$ and $60^{\circ}$; aspect ratios of 1,2 and 4 ; and $10^{3}<R a_{W}<$ $5 \times 10^{5}$. Correlations of $N u_{W}$ vs. $R a_{W}$ at each tilt angle are given.

In brief, the references above and others indicate that laminar flow exists for the standard two-dimensional problem for air up to Rayleigh numbers of about $10^{9}$. Further, the transition among cell structures in steady state for the standard problem can be fairly well predicted by numerical analysis; however, for the cavity heated from below, much less 
confidence can be placed on the predictions of steady-state solutions. In the bottom-heated cavity, there is a sequence of bifurcations to more complex flow cell configurations, and multiple numerical and physical solutions may exist for a given set of parameters. Because tilted cavities involve a transition from the well-behaved conditions of the standard problem to the less-well understood problem of the bottom-heated cavity, the tilted cavity problem also presents difficulties in numerical analysis.

\section{Three-Dimensional Cavities}

All of the factors that can cause difficulties in two-dimensional solutions are also present in three-dimensional simulations. In addition, it is known that imposing symmetry conditions on a numerical solution can cause the suppression of asymmetric solutions that are physically present.

\section{Differentially heated sidewalls}

Hiller et al. (1993) observed and numerically computed the transient onset of flow and heat transfer in a cube with opposite vertical walls instantaneously subjected to heating and cooling. All other surfaces were adiabatic. The system under study had $R a=1.66 \times 10^{5}$, and it was observed that the Nusselt number underwent transients such that at early times the Nusselt number exceeded the long-time (steady state) value by a factor of greater than 2 .

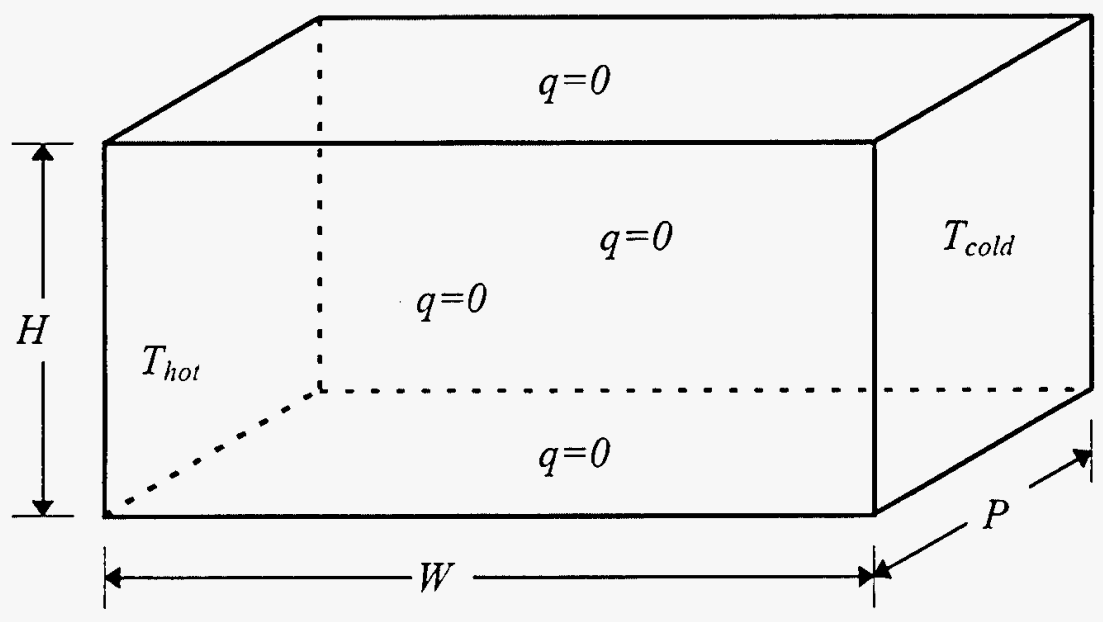

Figure A-2: Standard Configuration for Study of Free Convection in a Three-Dimensional Enclosure

Webb and Bergman (1992) used experiment and analysis to examine steady state free convection in a cavity with opposing sidewalls heated at constant heat flux and with all other cavity surfaces held at constant temperature. They observed strong three-dimensional flows in the cavity, but saw no asymmetries in the flow and so were able to impose 
symmetry conditions in the numerical analysis. A correlation of $N u$ vs. $G r$ is presented that represented all experimental results within an average error of \pm 5 percent with a maximum error of \pm 15 percent.

The standard 3-D cubic cavity problem with two of the opposite vertical walls heated and cooled and all other surfaces adiabatic is treated by Janssen et al. (1993). They also examined whether the imposition of symmetry conditions on the numerical solution changed the predictions, and concluded that it did not. For the case when the top and bottom surfaces were assumed to be perfectly conducting, they predict a transition from steady to periodic flow to occur at $2.25 \times 10^{6}<R a<2.35 \times 10^{6}$. They observed that transition to periodic flow occurred for air at somewhat higher Rayleigh number than for an equivalent 2-D square cavity, and that the amplitude of oscillations was strongly 3-D in nature. In a following paper, Janssen and Henkes (1995) extended the work to rectangular three-dimensional cavities, again with conducting top and bottom.

Fusegi et al. (1993) analyzed the effect on free convection to air of top, bottom, and two opposing vertical surfaces with finite (rather than infinite) thermal conductivity for a cubical enclosure with two differentially heated opposite vertical walls. As the wall conductivity was increased, various effects were observed; for example, if the horizontal surfaces had high thermal conductivity, then significant heat transfer in the vertical direction was predicted.

Hsieh and Wang (1994) performed transient free convection experiments on air, water, and silicone oil in a rectangular enclosure with differentially heated opposite vertical walls and the four other surfaces adiabatic. The enclosure had aspect ratios of $P / H=0.25,0.5,1$, 1.67 and 5 (although not all of these were used for both flow visualization and heat transfer measurements), for $P / W=5$, where $P$ is the heated plate width. The ranges of other parameters covered was $1 \times 10^{6}<R a_{H}<2 \times 10^{9}$ and $0.7<\operatorname{Pr}<457$. They concluded that Prandtl number has a strong effect, and that most heat transfer occurs because of boundary layer flows and that the stagnant inner core is not important.

Hsieh and Yang (1996) later performed transient free convection experiments on silicone oil alone in a rectangular enclosure with differentially heated opposite vertical walls and the four other surfaces adiabatic. The parameter values studied were $6.9 \times 10^{7}<R a_{H}<$ $4.12 \times 10^{8}, P r=457$, and aspect ratio of $P / H=0.33$ and $P / W=0.83$, where $P$ is the heated plate width. They found that the periodic oscillations observed in the experiment were up to six times longer than predicted by two-dimensional analyses.

Schöpf and Patterson (1996) used water in a square cavity with temperature differences on the vertical sidewalls to provide $6.9 \times 10^{8}>R a>4.9 \times 10^{8}$. The cavity was two times longer in the remaining dimension to approximate two-dimensional conditions. This experimental study used shadowgraphs to investigate the appearance of traveling waves along the heated vertical surface immediately after imposing a temperature increase, and the propagation of this wave and subsequent interactions with the thermal boundary layer development. Under some conditions, the traveling waves damped out with time and a steady-state pattern developed typical of most predictions; however, in some cases, the initial traveling wave proceeded with time to produce a periodic oscillatory flow in the cavity boundary layer. 


\section{Bottom heated cavities}

In a pair of papers, Mukutmoni and Yang (1993a,b) follow the development of free convection in a three-dimensional rectangular cavity heated at the bottom and cooled at the top with adiabatic side surfaces. Development progressed from pure conduction through stable cellular flow through oscillatory flow to chaotic flow for a fluid with Prandtl number of 2.5. The cavity has a size of 3.5:2.1:1, with unity being the vertical space between the heated and cooled plates. They found excellent agreement between their numerical predictions and available experiments, and were able to show that some paths through the period doubling of cells that are observed experimentally are difficult to predict by the numerical scheme. In a follow-on paper, (Mukutmoni and Yang, 1995) they were able to explain experimental results for a 2.42:1.23:1 cavity with a fluid with Prandtl number of 5 which underwent a bifurcation sequence that began in steady-state, and followed the path through periodic- quasi-periodic- steady state with increasing Rayleigh number. The reversion to steady state was seen through numerical analysis of the system to be caused by a change from a periodic simple three-dimensional flow configuration to a more complex three-dimensional configuration that is steady in character. Thus, temporal complexity was traded for structural complexity in the observed reversion to steady behavior.

Hernández and Frederick (1994) studied the effect of aspect ratio on the development of convective structures in an air-filled rectangular cavity with a square heated bottom wall and square cooled top wall at a fixed Rayleigh number of $8 \times 10^{3}$. Aspect ratios of $1<W / H<5$ were studied (discrete aspect ratios of $1,1.5,2,3,4$, and 5 were actually studied), and it was observed that a series of bifurcations of the flow structure occurred with increasing aspect ratio. However, the average Nusselt number was observed to increase with aspect ratio, although local values showed major pattern changes that depended on the roll structure that was present.

Pallarés et al. (1996) examined a cubical cavity filled with air heated from below and cooled from above with isothermal surfaces, and all other surfaces adiabatic. The limited the study to $3500<R a<10,000$. By solving the three-dimensional transient Navier-Stokes equations, and initiating the solution at various Rayleigh numbers with perturbations of \pm 0.05 of the temperature field, they determined that any of four different stable flow patterns could exist in this range. The Nusselt number tended to increase with Rayleigh number raised to a power in the range 0.7 to 0.4 for each of the structures. One of the structures was toroidal, and had a Nusselt number 65 percent smaller than that for any of the three predicted single-roll structures. This structure was only found for $R a$ above about 8000 .

\section{Tilted cavities}

Elsherbiny (1993) carried out experiments in a chamber that could be rotated to any angle. The cavity had the square long walls heat and cooled, and had conducting sidewalls. The cavity aspect ratios were $A=20$ and 80 , and rotations from 0 to $180^{\circ}$ were studied. Correlations for $\mathrm{Nu}$ vs. $R a_{H}$ in various ranges of tilt angle for air are presented for $10^{2}<R a_{H}<2 \times 10^{6}$. 


\section{Effect of throughflow}

The addition of laminar throughflow to the enclosure causes preferential alignment of the roll cells, and may alter the predicted heat transfer considerably. Chen and Lavine (1995) examine a bottom-heated cavity and compute the three-dimensional free convective patterns in air as affected by throughflow. The duct considered had an aspect ratio of 2 perpendicular to the flow direction, and calculations were performed for a position far downstream from the flow entrance. Parametric variations were over the range $2000<R a_{H}$ $<4000,1<R e_{H}<20$. The time averaged and space averaged Nusselt numbers were found to be independent of $R e_{H}$, and only dependent on $R a_{H}$, whether the flow characteristics were spanwise rolls or transverse rolls.

\section{Turbulent Free Convection}

\section{Two-Dimensional Cavities}

Nieuwstadt (1990) has shown that turbulent flow is inherently three-dimensional, and therefore two-dimensional solutions of turbulent natural convection are often unrealistic. Nieuwstadt used direct simulation and large-eddy simulation to calculate free convection in flows between parallel surfaces, but notes that three-dimensional enclosures inherently are governed by boundary layer flows where small eddies dominate and other models must be invoked. Further, many of the conditions necessary for implementation of standard turbulence models such as $k-\varepsilon$ are not met in cavity flows. Because calculations of Nusselt number may provide accurate results even though the model is on a shaky physical basis, good comparison with experimental Nusselt numbers does not necessarily imply that a particular numerical model is accurate in predicting all aspects of the fluid flow and heat transfer in a cavity. For these reasons, solutions for two-and three-dimensional turbulent cavity flows are open to considerable question.

\section{Differentially heated sidewalls}

Nobile et al. (1990) used the $k-\varepsilon$ model to study turbulent free convection for air in the standard square cavity for $10^{7}<R a<10^{10}$, and found considerable differences compared with some earlier work. They also modeled water for a cavity with aspect ratio of 0.1 at $R a_{H}=8 \times 10^{10}$, and compared their results with experimental data. Agreement in trends was correct, but some parameters at some locations were poorly predicted.

Henkes and Hoogendoorn (1994) used the standard $k-\varepsilon$ formulation as well as two lowReynolds number $k-\varepsilon$ formulations to analyze turbulent free convection of air and water in a square enclosure with differentially heated side walls. Steady solutions were found up to $R a_{H}=10^{20}$ for the standard model, and up to $\sim 10^{17}$ for the low-Reynolds models. Scaling parameters are presented for cavity flows based on the results.

Hanjalic' and Vasic' (1993) used an algebraic flux model for the turbulent heat flux vector along with a low Reynolds number $k-\varepsilon$ model to treat free convection in the standard 
problem for air in a square cavity and in a cavity with $A=0.2$. The study covered $10^{10}<$ $R a_{H}<10^{12}$. They propose a correlation of the form

$$
N u_{H}=0.048 R a_{H}^{1 / 3}
$$

for turbulent free convection in the standard problem. The result is independent of aspect ratio over the range $0.2<A<1$.

\section{Tilted cavities}

Kuyper et al. (1993) extended their laminar flow work to high Rayleigh numbers using a standard $k-\varepsilon$ model and a $k-\varepsilon$ model without wall functions. They examined free convection of air for a square cavity over Rayleigh up to $10^{11}$ for cavity inclinations of $0^{\circ}$ (heated from below) to $180^{\circ}$ (heated from above). The connecting walls were adiabatic. They found that transition to chaotic flow and the onset of turbulence depended not only on tilt angle, but that there was a hysterisis effect on Nusselt number vs. tilt angle depending on the sign of the rotation in approaching a given tilt. They provide correlations of mean Nusselt number vs. Rayleigh number for various tilt angles and Rayleigh number ranges.

A similar case was studied by Ben Yedder and Bilgen (1995), except that the cooled wall was assumed to be a thick material of known conductivity connected with an isothermal surface on the exterior of the cavity. A constant heat flux was imposed on the heated wall to simulate a solar collector. They used a $k$ - $\varepsilon$ model to examine free convection of air for a square cavity over $10^{8}<R a_{W}<10^{12}$, aspect ratios from 0.5 to 1 , wall to fluid thermal conductivity ratios in the range 1 to 10 , various wall thicknesses from 0 to $0.5 \mathrm{~W}$, and cavity inclinations of $0^{\circ}$ (heated from below) to $180^{\circ}$ (heated from above). Heat transfer increased with Rayleigh number, conductivity ratio, decreased with wall thickness, and reached a maximum at tilt angle between 80 and $90^{\circ}$.

Upton and Watt (1997) measured velocity and temperature profiles in a square enclosure at $R a=1.5 \times 10^{5}$ for inclination angles of $\pi / 4, \pi / 2$, and $3 \pi / 4$. Evolution to steady flow was observed

\section{Three-Dimensional Cavities}

\section{Bottom heated cavities}

The effects of a sawtooth temperature transient on the bottom surface of heated cavity containing water was measured by Mantle et al. (1994) for different amplitudes over the range $0.4 \times 10^{8}<R a_{H}<1.2 \times 10^{9}$ using a square heater plate with an aspect ratio of 4 . It was found that there was little effect on convective transfer unless the amplitude of the sawtooth exceeded 30 percent of the average temperature difference between the heated and cooled plates. In that case, for some periods of oscillation, the heat transfer was increased by up to $12 \%$. The steady state heat transfer measurements were well correlated within the given Rayleigh number range by:

$$
N u_{H}=0.087 R a_{H}^{0.312}
$$




\section{REFERENCES}

Abib, A.H. and Jaluria, Y., 1995, "Turbulent Penetrative and Recirculating Flow in a Compartment Fire," ASME J. Heat Transfer, vol. 117, no. 4, pp. 927-934, November.

Balaji, C. and Venkateshan, S.P., 1994, "Combined Surface Radiation and Free Convection in Cavities," AIAA J. Thermophysics Heat Transfer, vol.8, no. 2, pp. 373-376, May-July.

Ben Yedder, R. and Bilgen, E., 1995, "Turbulent Natural Convection and Conduction in Enclosures Bounded by a Massive Wall," Int. J. Heat Mass Transfer, vol. 38, no. 10, pp. 1979-1891.

Boehrer, B., 1997, "Convection in a Long Cavity with Differentially Heated End Walls," Int. J. Heat Mass Transfer, vol. 40, no. 17, pp. 4105-4114.

Chen, S.S. and Lavine, A.S., 1996, "Laminar, Buoyancy Induced Flow Structures in a Bottom Heated, Aspect Ratio 2 Duct with Throughflow," Int. J. Heat Mass Transfer, vol. 39 , no. 1, pp. 1-11.

Clauss, D.B., et al. "Defense Programs Transportation Risk Assessment: Probabilities and Consequences of Accidental Dispersal of Radioactive Material Arising from Off-Site Transportation of Defense Programs Material (U)," SAND93-1671, Sandia National Laboratories, September 1994, Secret Restricted Data.

Clauss, D.B., et al., "A Statistical Description of the Types and Severities of Accidents Involving Tractor Semi-Trailers," SAND93-2580, Sandia National Laboratories, June 1994.

Cooper, L.Y., 1995, "Combined Buoyancy and Pressure-Driven Flow through a Shallow, Horizontal, Circular Vent," ASME J. Heat Transfer, vol. 117, no. 3, pp. 659-667, August.

Daniels, P.G. and Wang, P., 1994, "Numerical Study of Thermal Convection in Tall Laterally Heated Cavities," Int. J. Heat Mass Transfer, vol. 37, no. 3, pp. 375-386.

de Groh, H.C. III and Kassemi, M., 1993, "Effect of Radiation on Convection in a TopHeated Enclosure," AIAA J. Thermophysics Heat Transfer, vol.7, no. 4, pp. 561-568, Oct.Dec.

de Vahl Davis, G., 1983, "Natural Convection of Air in a Square Cavity: A Bench Mark Numerical Solution," Int. J. Num. Meths. in Fluids, vol. 3, no. 3, pp. 249-264.

Dinenno, P.J., ed., National Fire Protection Association, "The SFPE Handook for Fire Protection Engineering," 1st edition, SFPE 8-88.

Ehlert, J.R. and Smith, T.F., 1994, "Surface Radiation for Rectangular Enclosures Using the Discrete Ordinates Method," AIAA J. Thermophysics Heat Transfer, vol.8, no. 3, pp. 628-631, July-Sept.

Elsherbiny, S.M., 1996, "Free Convection in Inclined Air Layers Heated from Above," Int. J. Heat Mass Transfer, vol. 39, no. 18, pp. 3925-3930. 
Fang, Z. and Paraschivoiu, 1992, "Numerical Solutions of Natural Convection in Enclosure with Boundary Condition Switching Method," AIAA J. Thermophysics Heat Transfer, vol. 6, no. 2, pp. 265-272, April-June.

Farmer, Jeff T., 1995, Improved Algorithms for Monte Carlo Analysis of Radiative Transfer in Complex Participating Media, PhD Dissertation, Department of Mechanical Engineering, The University of Texas, August.

Fusegi, T., Hyun, J.M., Kuwahara, K. 1993, "Three-dimensional Natural Convection in a Cubical Enclosure with Walls of Finite Conductance," Int. J. Heat Mass Transfer, vol. 36, no. 7, pp. 1993-1997.

Ganzarolli, M.M. and Milanez, L.F., 1995 "Natural Convection in Rectangular Enclosures Heated from Below and Symmetrically Cooled from the Sides," Int. J. Heat Mass Transfer, vol. 38, no. 6, pp. 1063-1073.

Guelzim, A., Souil, J.M., and Vantelon, J.P., 1993, "Suitable Configuration Factors for Radiation Calculation Concerning Tilted Flames," ASME J. Heat Transfer, vol. 115, no. 2, pp. 489-492, May.

Hanjalic', K. and Vasic', S., 1993, "Computation of Turbulent Natural Convection in Rectangular Enclosures with an Algebraic Flux Model," Int. J. Heat Mass Transfer, vol. 36 , no. 14 , pp. 3603-3624.

Hasnaoui, M., Bilgen, E., and Vasseur, P., 1992, "Natural Convection Heat Transfer in Rectangular Cavities Partially Heated from Below," AIAA J. Thermophysics Heat Transfer, vol. 6, no. 2, pp. 255-264, April-June.

Hassani, A.V. and Hollands, K.G.T., 1989, "On Natural Convection Heat Transfer from Three-Dimensional Bodies of Arbitrary Shape," ASME J. Heat Transfer, vol. 111, no. 2, pp. 363-371, May.

Hayasaka, H., Koseki, H., and Tashiro, Y., 1992, "Radiation Measurements in Large-scale Kerosene Flames Using High-speed Thermography," Fire Technology, vol. 28, no. 2, pp. 110-122, May.

Henkes, R.A.W.M., and Hoogendoorn, C.J., 1993, "Scaling of the Laminar NaturalConvection Flow in a Heated Square Cavity," Int. J. Heat Mass Transfer, vol. 36, no. 11, pp. 2913-2925.

Henkes, R.A.W.M., and Hoogendoom, C.J., 1994 "Scaling of the Turbulent NaturalConvection Flow in a Heated Square Cavity," ASME J. Heat Transfer, vol. 116, no. 2, pp. 400-408, May.

Hernandez, R. and Frederick, R.L., 1994, "Spatial and Thermal Features of ThreeDimensional Rayleigh-Bénard Convection," Int. J. Heat Mass Transfer, vol. 37, no. 3, pp. 411-424.

Hiller, W.J., Koch, St., Kowalewski, T.A., and Stella, F., 1993, "Onset of Natural Convection in a Cube," Int. J. Heat Mass Transfer, vol. 36, no. 13, pp. 3251-3263. 
Hsieh, S.-S. and Wang, C.-Y., 1994, "Experimental Study of Three-Dimensional Natural Convection in Enclosures with Different Working Fluids," Int. J. Heat Mass Transfer, vol. 37, no. 17, pp. 2687-2698.

Hsieh, S.-S. and Yang, S.-S., 1996, "Transient Three-Dimensional Natural Convection in a Rectangular Enclosure," Int. J. Heat Mass Transfer, vol. 39, no. 1, pp. 13-26.

Janssen, R.J.A., Henkes, R.A.W.N., and Hoogendoorn, C.J., 1993, "Transition to TimePeriodicity of a Natural-Convection Flow in a 3D Differentially Heated Cavity," Int. $J$. Heat Mass Transfer, vol. 36, no. 11, pp. 2927-2940.

Janssen, R.J.A.and Henkes, R.A.W.N., 1995, "The First Instability Mechanism in Differentially Heated Cavities with Conducting Horizontal Walls," ASME J. Heat Transfer, vol. 117, no. 3, pp. 626-633, August.

Kangni, A., Vasseur, P., and Bilgen, E., 1995, "Natural Convection in Inclined Enclosures with Multiple Conducting Partitions," AIAA J. Thermophysics Heat Transfer, vol. 9, no. 2, pp. 270-277, April-June.

Keyhani, M. and Dalton, T., 1996, "Natural Convection Heat Transfer in Horizontal RodBundle Enclosures," ASME J. Heat Transfer, vol. 118, no. 3, pp. 598-605, August.

Kuo, D.-C., 1996, Application of Spectral Methods for Simulating Transport Phenomena, $\mathrm{PhD}$ Dissertation, Department of Mechanical Engineering, The University of Texas, July, 1996.

Kuyper, R.A., van der Meer, Th. H., Hoogendoorn, C.J., and Henkes, R.A.W.M., 1993, "Numerical Study of Laminar and Turbulent Natural Convection in an Inclined Square Cavity," Int. J. Heat Mass Transfer, vol. 36, no. 11, pp. 2899-2911.

Larsen, Marvin E., 1994, "MELTER: A Model of the Thermal Response of Cargos Transported in the Safe-Secure Trailer Subject to Fire Environments for Risk Assessment Applications," Sandia Rept. SAND93-0737•UC-722, August.

Le Quéré, P., and Alziary de Roquefort, T., 1988, "Transition to Unsteady Natural Convection of Air in Vertical Differentially Heated Cavities: Influence of Thermal Boundary Conditions on the Horizontal Walls,' Proc. Eighth Int. Heat Transfer Conf., vol. 4, pp. 1533-1538.

Lykoudas, P.S., 1995, "Introduction to the Method of Average Magnitude Analysis and Application to Natural Convection in Cavities," ASME J. Heat Transfer, vol. 117, no.3, pp. 604-610, August.

Mantle, J., Kazmierczak, M. and Hiawy, B., 1994, "The Effect of Temperature Modulation on Natural Convection in a Horizontal Layer Heated from Below: High-Rayleigh-Number Experiments," ASME J. Heat Transfer, vol. 116, no.3, pp. 614-620, August.

Modest, Michael, 1993, Radiative Heat Transfer, McGraw-Hill, New York. 
Mukutmoni, D. and Yang, K.T., 1993a, "Rayleigh-Bénard Convection in a Small Aspect Ratio Enclosure: Part II-Bifurcation to Oscillatory Convection," ASME J. Heat Transfer, vol. 115, no. 2, pp. 360-366, May.

Mukutmoni, D. and Yang, K.T., 1993b, "Rayleigh-Bénard Convection in a Small Aspect Ratio Enclosure: Part II-Bifurcation to Chaos," ASME J. Heat Transfer, vol. 115, no. 2, pp. 367-376, May.

Mukutmoni, D. and Yang, K.T., 1995, "Thermal Convection in Small Enclosures: An Atypical Bifurcation Sequence," Int. J. Heat Mass Transfer, vol. 38, no. 1, pp. 113-126.

Nicholas, J.D. and Nansteel, M.W., 1993, "Natural Convection in a Rectangular Enclosure with Partial Heating of the Lower Surface: Experimental Results," Int. J. Heat Mass Transfer, vol. 36, no. 16, pp. 4067-4071.

Nieuwstadt, F.T.M., 1994, "Direct and Large-Eddy Simulation of Free Convection," Proc. $9^{\text {th }}$ Int. Heat Transfer Conf., vol. 1, pp. 37-47.

Nobile, E., Sousa, A.C.M., and Barozzi, G.S., 1990, "Turbulent Buoyant Flows in Enclosures," Proc. Ninth Int. Heat Transfer Conf., vol. 2, pp. 543-548, August, Jerusalem.

Ostrach, S., 1988, "Natural Convection in Enclosures," ASME J. Heat Transfer, vol. 110, no. 4, pp. 1175-1190, November.

Ozoe, H., 1993, "Three-Dimensional Numerical Analysis of Natural and Mixed Convection of Liquid Metal With and Without External Magnetic Field," in Computers and Computing in Heat Transfer Science and Engineering, W. Nakayama and K.T. Yang, eds., pp. 5-22, $\mathrm{CRC} /$ Begell House, New York.

Pallarés, J., Cuesta, I., Grau, F. X., and Girault, F., 1996, "Natural Convection in a Cubical Cavity Heated from Below at Low Rayleigh Numbers," Int. J. Heat Mass Transfer, vol. 39, no. 15, pp. 3233-3247.

Rammohan Rao, V., Balaji, C. and Venkateshan, S.P., 1997, "Interferometric Study of Interaction of Free Convection with Surface Radiation in an L Comer," Int. J. Heat Mass Transfer, vol. 40, no. 12, pp. 2941-2947.

Ruhul Amin, R., 1993a, "Natural Convection Heat Transfer in Enclosures Fitted with a Periodic Array of Hot Roughness Elements at the Bottom," Int. J. Heat Mass Transfer, vol. 36, no. 3, pp. 755-763, March.

Ruhul Amin, R., 1993b, "Natural Convection Heat Transfer and Fluid Flow in an Enclosure Cooled at the Top and Heated at the Bottom with Roughness Elements," Int. J. Heat Mass Transfer, vol. 36, no. 10, pp. 2707-2710.

Schöpf, W. and Patterson, J.C., 1996, "Visualization of Natural Convection in a SideHeated Cavity: Transition to the Final Steady State," Int. J. Heat Mass Transfer, vol. 36, no. 16 , pp. 3497-3509, October. 
Showhole, R.A. and Tarasuk, J.D., 1993, "Experimental and Numerical Studies of Natural Convection with Flow Separation in Upward-Facing Inclined Open Cavities," ASME J. Heat Transfer, vol. 115, no.3, pp. 592-605, August.

Siegel, Robert and Howell, John R., 1992, Thermal Radiation Heat Transfer, Taylor \& Francis-Hemisphere, New York.

Singhal, M. and Kumar, R., 1995, "Unsteady Buoyancy Exchange Flow Through a Horizontal Partition," ASME J. Heat Transfer, vol. 117, no. 2, pp. 515-520, May.

Soong, C.Y., Tzeng, P.Y., Chiang, D.C. and Sheu, T.S., 1996, "Numerical Study on ModeTransition of Natural Convection in Differentially Heated Inclined Layers," Int. J. Heat Mass Transfer, vol. 39, no. 14, pp. 2869-2882.

Steckler, K., Baum, H., and Quintiere, J., 1984, "Fire Induced Flows Through Room Openings-Flow Coefficients," Twentieth Symposium (International) on Combustion, The Combustion Inst., pp. 1591-1600.

Upton, T.D. and Watt, D.W., 1997, "Experimental Study of Transient Natural Convection in an Inclined Rectangular Enclosure," Int. J. Heat Mass Transfer, vol. 40, no. 11, pp. 2679-2690.

Wang, P. and Daniels, P.G., 1994, "Numerical Study of Thermal Convection in Shallow Cavities with Conducting Boundaries," Int. J. Heat Mass Transfer, vol. 37, no. 3, pp. 387399.

Wakitani, S., 1997, "Development of Multicellular Solutions in Natural Convection in an Air-Filled Vertical Cavity," ASME J. Heat Transfer, vol. 119, no. 1, pp. 97-101, February.

Warrington, R.O. and Crupper, G., 1981, "Natural Convection Heat Transfer between Cylindrical Tube Bundles and a Cubical Enclosure," ASME J. Heat Transfer, vol. 103, no. 1, pp. 103-107, February.

Webb, B.W. and Bergman, T.L., 1992, "Three-Dimensional Natural Convection from Vertical Heated Plates with Adjoining Cool Surfaces," ASME J. Heat Transfer, vol. 114, no. 1, pp. 115-120, February.

Webb, B.W. and Viskanta, R., 1987, "Radiation-Induced Buoyancy-Driven Flow in Rectangular Enclosures: Experiment and Analysis," ASME J. Heat Transfer, vol. 109, no. 2, pp. 427-433, May

Xia, Q., Yang, K.T., and Mukutomi, D., 1995, "Effect of Imposed Wall Temperature Oscillations on the Stability of Natural Convection in a Square Enclosure," ASME J. Heat Transfer, vol. 117, no. 1, pp. 113-120, February.

Yang, K.T., 1986, "Numerical Modeling of Natural Convection-Radiation Interactions in Enclosure," Proc. Eighth Int. Heat Transfer Conf., vol. 1, pp. 131-140, August, San Francisco.

Yang, K.T., 1988, "Transitions and Bifurcations in Laminar Buoyant Flows in Confined Enclosures," ASME J. Heat Transfer, vol. 110, no. 4, pp. 1191-1204, November. 
Yang, K.T. and Mukutmoni, D., 1993, "Computational Aspects of Studies of Buoyant Enclosure Flows," in Computers and Computing in Heat Transfer Science and Engineering, W. Nakayama and K.T. Yang, eds., pp. 23-41, CRC/Begell House, New York.

Zhao, Z., Poulikakos, D., and Ren, Z., 1992, "Combined Natural Convection and Radiation from Heated Cylinders Inside a Container," AIAA J. Thermophysics Heat Transfer, vol. 6, no. 4, pp. 713-720, Oct.-Dec.

Zia, J.L., Xin, M.D., and Zhang, H.J., 1990, "Natural Convection in an Externally Heated Enclosure Containing a Local Heat Source," AIAA J. Thermophysics Heat Transfer, vol. 4, no. 2, pp. 233-238, April. 


\section{SYMBOLS}

$A$ aspect ratio, $W / H$

$c_{P} \quad$ specific heat at constant pressure, $\mathrm{kJ} /(\mathrm{kg} \cdot \mathrm{K})$

$D$ diameter, $\mathrm{m}$

$h \quad$ heat transfer coefficient, $\mathrm{W} /\left(\mathrm{m}^{2} \bullet \mathrm{K}\right)$

$H$ height of enclosure, $\mathrm{m}$

$k$ thermal conductivity, $\mathrm{W} /(\mathrm{m} \cdot \mathrm{K})$

$L \quad$ characteristic length, $\mathrm{m}$

$N u_{L} \quad$ Nusselt number, $h L / k$

$P \quad$ depth of rectangular three-dimensional enclosure

Pr Prandtl number, $c_{P} \mu / k$

$q \quad$ energy flux, $\mathrm{kW} / \mathrm{m}^{2}$

$R \quad$ radius, $\mathrm{m}$

$R a_{L} \quad$ Rayleigh number, $g \beta \Delta T L^{3} / v \alpha$

Re Reynolds number, $L u / v$

$T$ absolute temperature, $\mathrm{K}$

$t$ time, $\mathrm{s}$

$u$ mean flow velocity, $\mathrm{m} / \mathrm{s}$

$W \quad$ width of enclosure, $m$

$\alpha \quad$ thermal diffusivity, $k /\left(\rho c_{P}\right), \mathrm{m}^{2} / \mathrm{s}$

$\beta \quad$ thermal expansion coefficient, $\mathrm{K}^{-1}$

$\varepsilon \quad$ radiative emissivity

$\mu \quad$ dynamic viscosity, $\mathrm{kg} /(\mathrm{m} \bullet \mathrm{s})$

$\nu$ kinematic viscosity, $\mu \rho, \mathrm{m}^{2} / \mathrm{s}$

$\rho$ density, $\mathrm{kg} / \mathrm{m}^{3}$

$\sigma \quad$ Stefan-Boltzmann constant, $5.66 \times 10^{-8} \mathrm{~W} /\left(\mathrm{m}^{2} \cdot \mathrm{K}^{4}\right)$

\section{Subscripts}

c cold

h hot

rad radiation 


\section{Distribution}

4 J.R. Howell

Department of Mechanical Engineering

The University of Texas at Austin

Austin, TX 78712-1063

$1 \quad$ MS0767

B. D. Boughton, 9141

$1 \mathrm{MS} 0865$

T. Y. Chu, 9135

1 MS0767

D. B. Clauss, 6314

1 MS0826

C. E. Hickox, 9111

$8 \quad$ MS0767

M. E. Larsen, 6314

$1 \quad$ MS0767

B. W. Marshall, Jr., 6314

1 MS0865 J. L. Moya, 9135

1 MS9018 Central Technical Files, 8940-2

2 MS0899 Technical Library, 4916

2 MS0619 Review \& Approval Desk, 12690 For DOE/OSTI 


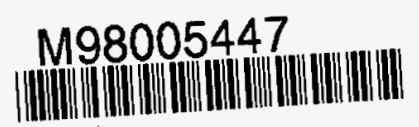

Report Number (14) SAND $-98-1076$

Jubl. Date (11) 199805
Sponsor Code (18) DOE $10 P, X F$
$J C$ Category (19) UC-722, DOE/ER 